\title{
OVERVIEW OF HIGH-LEVEL RADIOACTIVE WASTE MANAGEMENT STUDIES
}

\section{AUGUST 1973}

Pacific Northwest Laboratories

Richland, Washington 99352 


\section{DISCLAIMER}

The summary material included in this report is intended to give an overview of activilies, sponsored by the U.S. Atomic Energy Commission, Division of Waste Management and Transportation (AEC-DWMT), that are being conducted by the Pacific Northwest Laboratory iPNL, operated for the AEC by Battelle). The report discusses the basic approach used and the accumpanying rationale for this work.

The activities described in this report are subject to modification based on new intormation which may be developed or changes in task emphasis. The report should not be construed at reflecting policies or programs that are to be implemented for the management of radioactive waste.

This report was prepared as an account of work sponsored by the United State Government. Neither the United States nor the U.S. Atomic Energy Commission, nor any of their employees, nor any of their contractors, subcontractors, or their employees, makes any warranty, express or implied, or assumes any legal liability or responsibility for the accuracy, completeness or usefulness of any information, apparatus, product or process disclosed, or represents that its use would not infringe privately owned rights. 


\title{
OVERVIEW \\ OF HIGH-LEVEL RADIOACTIVE \\ WASTE MANAGEMENT STUDIES
}

\author{
Nuclear Waste Technology \\ Department
}

AUGUST 1973

BATTELLE

PACIFIC NORTHWEST LABORATORIES

RICHLAND, WASHINGTON 99352 


\section{CONTENTS}

\begin{tabular}{|c|c|c|c|c|c|c|c|c|c|c|c|}
\hline INTRODUCTION & • & - & . & - & • & . & - & - & . & . & \\
\hline SUMMARY & . & . & . & - & . & . & - & - & . & • & \\
\hline Waste Fixation & . & . & - & . & . & $\cdot$ & - & . & . & . & \\
\hline Advanced Disposal & Conc & epts & . & . & • & . & . & . & . & • & \\
\hline WASTE FIXATION PROG & RAM & . & - & - & • & $\cdot$ & . & - & - & $\cdot$ & \\
\hline Commercial Waste & Studi & & . & . & . & - & . & - & . & • & \\
\hline AEC Waste Studies & • & - & - & - & · & • & - & - & - & - & \\
\hline Product Evaluatio & & . & - & . & · & . & - & - & . & . & \\
\hline ADVANCED CONCEPTS $F$ & OR DI & SPOSAL & OF & $H I G H-L$ & LEVEL & & OACT I & VE & WASTE & - & \\
\hline Evaluation Factor & & . & . & - & . & . & . & . & . & . & \\
\hline Radiological Eval & uatio & & - & - & - & $\cdot$ & - & $\cdot$ & - & $\cdot$ & \\
\hline Geologic Disposal & - & • & - & - & • & $\cdot$ & · & · & - & $\cdot$ & \\
\hline Seabed Disposal & $\cdot$ & - & - & $\cdot$ & - & - & • & $\cdot$ & - & - & \\
\hline Ice Sheet Disposa & & • & - & - & • & • & • & - & - & - & \\
\hline Extraterrestrial & Dispo & sal & . & . & · & • & • & - & - & · & \\
\hline Transmutation & . & . & . & . & • & • & - & . & - & - & \\
\hline WASTE PARTITIONING & - & . & - & . & $\cdot$ & • & - & - & . & - & \\
\hline
\end{tabular}




\section{LIST OF FIGURES}

1 High-Level Radioactive Waste Anticipated from the Nuclear Industry - 2

2 Spray Calciner and Continuous Silicate Glass Melter . . . . 8

3 Fluidized Bed Calciner and Continuous Silicate Glass Melter . 9

4 Waste Management Logic Diagram • . • . • • . . 13

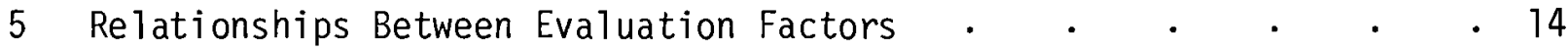

6 Radiation Exposure Pathways to People Living in an Environment Containing Trace Amounts of Radioactivity ..$\quad \cdot \quad \cdot \quad \cdot \quad \cdot 17$

7 Interrelation Between Pathway, Probability and Risk . . . . 18

8 Solidified Waste in Mined Cavity . . . . . . . . 20

9 Solidified Waste in Man-Made Structure in Geologic Formation,

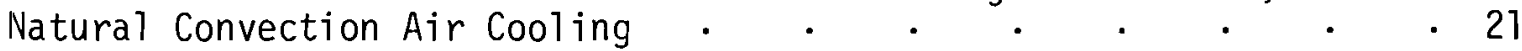

10 Deep Drilled Hole Concept, Solid Emplacement, In-Place Conversion to Rock-Waste Matrix . . . . . . . . . . 22

- 11 Mined Cavity Concept, Liquid Emplacement, In-Place Solidification . 22

12 Operations in Seabed Disposal . $\quad . \quad$. $\quad . \quad$. $\quad . \quad$. $\quad$. 25

13 Seabed: Subduction Zones, Margins of Certain Crustal Plates . . 26

14 Seabed: Deep Trenches. . . . . . . . . . . 26

15 Seabed: Stable Deep Sea Floor . . . . . . . . . 26

16 Seabed: High Sedimentation Rate Areas . . . . . . . 27

17 Operations in Ice Sheet Disposal . . . . . . . . . 28

18 Ice Sheet: Free Flow Waste Canister Melts Down to Bedrock . . 29

19 Ice Sheet: Anchored Storage, Predetermined Depth . . . . 29

20 Ice Sheet: Surface Storage Facility . . . . . . . 30

21 Extraterrestrial Waste Encapsulation and Containment Concept . . 31

22 Escape Velocity Required for Various Extraterrestrial Disposal

Modes and Current Space Vehicle Performance Characteristics . . 33

23 Centaur Orbit-to-Orbit Shuttle Launch Deployment Sequence . . 34

24 Transmutation Waste Management Strategy . • • • •

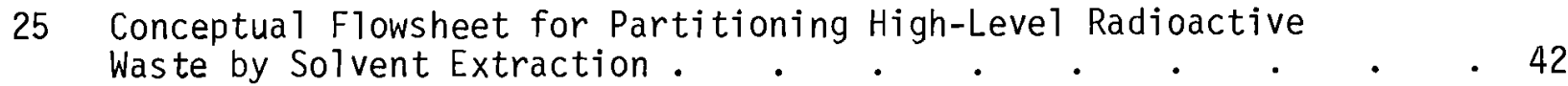




\section{OVERVIEW \\ OF HIGH-LEVEL RADIOACTIVE \\ WASTE MANAGEMENT STUDIES}

\section{INTRODUCTION}

The production of electrical power from nuclear energy involves several major functions:

- Preparation of nuclear reactor fuel

- Reactor operation and conversion of heat energy from the reactor into electrical power

- Reprocessing discharged fuel for removal of waste and recovery of useful fuel materials for recycle.

As the reactor is operated, fission takes place in the reactor fuel and, as a result, a portion of the fuel must be periodically discharged for removal of the waste products and replacement with new fuel. The discharged reactor fuel still contains enough valuable uranium and plutonium isotopes to make their recovery, by fuel reprocessing, and subsequent recycle through the fuel preparation step economical.

The nuclear wastes resulting from the fuel reprocessing operation must be handled in a carefully controlled manner since they contain numerous radioactive isotopes. A major waste stream, termed "high-level waste", is produced as a liquid in the first cycle solvent extraction step of the fuel reprocessing operation. This waste stream contains most of the reactorproduced fission products and actinides as well as uranium and plutonium isotopes that are not separated during reprocessing because of process limitations. The anticipated production of high-level nuclear waste is shown in Figure 1.

This high-level waste must be safely contained for many thousands of years to allow the waste components to be transformed to nonradioactive 


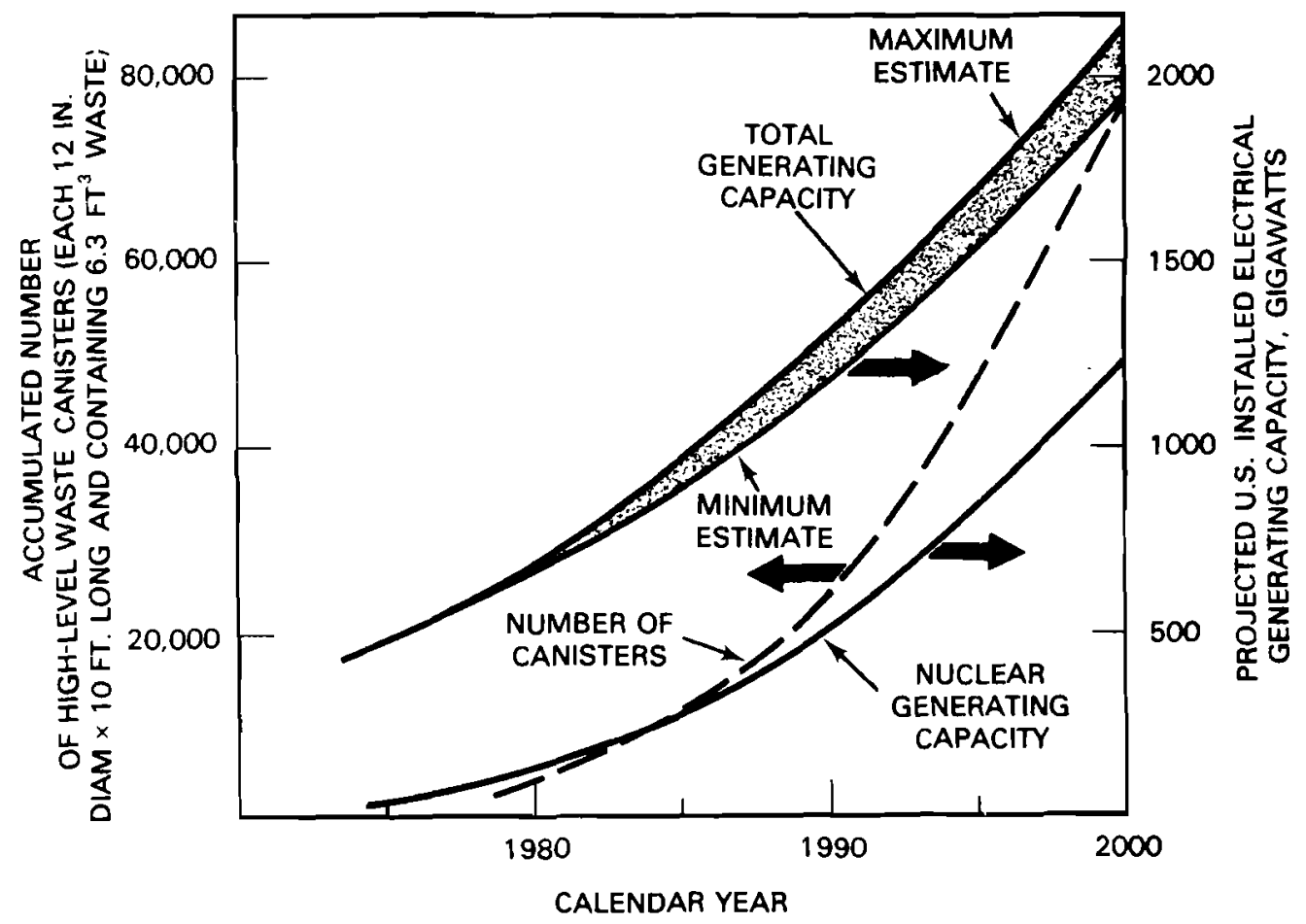

Note: - At the time of canister loading, typically about 10 years after fuel (which contains "high-level waste") discharge from a reactor, each canister would contain about 6.3 cubic feet of solidified high-level waste (waste from about 3 metric tons of fuel), about 1 million curies of radioactive material, with a heat generation rate of approximately 3,000 watts

- 1 gigawatt $=10^{9}$ watts

FIGURE 1. High-Leve1 Radioactive Waste Anticipated from the Nuclear Industry

materials by radioactive decay. As an example, the half-life* of the plutonium isotope ${ }^{239} \mathrm{Pu}$ is 24,000 years.

Present Atomic Energy Commission (AEC) regulations require that the liquid high-level waste from fuel reprocessing be 1) converted to a solid material within 5 years after separation in the fue 1 reprocessing step, and 2) that it be encapsulated and shipped to a federal repository within 10 years of its production for 1ong-term management by the AEC.

* Half-life - The time required for a radioactive substance to 10 se $50 \%$ of its activity by radioactive decay. 
The AEC is sponsoring the development and demonstration of technology for long-term waste management in studies conducted by various government laboratories and private industry. Numerous waste management options are being investigated including:

- Retrievable surface (or near-surface)storage and surveillance for extended time periods

- Pilot-scale studies on the use of bedded salt for retrievable storage and possibly ultimate disposal

- Ultimate disposal in alternative terrestrial locations or extraterrestrially in space

- Elimination of the long half-life radioactive waste by a strategy that includes separation of specific nuclides, and nuclear transmutation to stable or shorter half-life material.

The Pacific Northwest Laboratory (PNL, operated for the AEC by Battelle) is investigating methods of ultimate disposal as alternatives to the bedded salt disposal plan (see page 7). In addition, a program on developing technology for converting the waste to a stable solid for storage and/or disposal is being conducted. 


\section{SUMMARY}

Technology related to the management of high-level radioactive waste is being developed at several government laboratories. Two of the major areas being investigated by Battelle at the Pacific Northwest Laboratory (PNL) are:

- Waste Fixation - Conversion of the waste to a stable solid form

- Advanced Disposal Concepts - A systematic evaluation of candidate disposal methods.

\section{Waste Fixation}

An added safety factor to most means of waste storage (temporary and retrievable) and waste disposal (permanent, and nonretrievable or possibly retrievable) could be provided by waste fixation. Technology is being developed through the pilot plant scale to incorporate the high-level waste into extremely immobile solid forms. The objective of these forms is to minimize the possible rate of waste release to man's environment should the containment system for the waste be breached. Specific investigations are currently centered on the production of stable, low solubility silicate glasses. The rate at which the radioactive waste in this form would dissolve in water, for example, may be less than the rate common bottle glass would dissolve under similar conditions.

\section{Advanced Disposal Concepts}

Alternative concepts for ultimate disposal of solidified high-level radioactive wastes are being evaluated on a systematic basis. The evaluation includes consideration of technical feasibility, safety, cost, environmental impact, policy conflicts, public acceptance and research and development needs. Waste disposal concepts under evaluation include geologic, seabed, ice sheet and extraterrestrial disposal as well as transmutation (transforming by irradiating certain waste constituents into elements having more desirable waste management characteristics).

As a complement to studies on waste fixation and advanced disposal concepts, studies are being conducted on waste partitioning (separation of 
radionuclides in waste into different elements or goups of elements according to their suitability for different disposal methods). Application of this technique is useful for some disposal alternatives and it may improve overall waste disposal technology. In addition, radiological evaluations are being conducted to assess by what means radionuclides in waste could contact man, assuming the primary waste containment barrier fails. 
WASTE FIXATION PROGRAM 


\section{WASTE FIXATION PROGRAM}

Until June 1971, the AEC high-level radioactive waste disposal plan was to dispose of the solid waste in a bedded salt deposit after conversion of the waste to a highly stable solid form (waste fixation). The waste containment had to remain intact only 90 days, after which time the waste was to be naturally and permanently sealed into the salt formation. The criterion for the waste was that it be a dry stable solid that could be safely handled and transported to the salt mine for permanent disposal. The current plan provides retrievable waste storage and surveillance for extended time periods and allows time for further developments leading to waste disposal decisions. As a result there is greater interest in developing better solid waste forms that will further minimize the possibility of radioactivity release under any handling or storage condition, in addition to providing an extra margin of safety to the waste disposal concept ultimately chosen.

Present AEC efforts are focused on development of solid silicate glasses and ceramics which incorporate the waste. The silicate products developed so far have low leach rates and low dispersibility. They are also fairly noncorrosive to waste containment materials.

\section{Commercial Waste Studies}

The present fixation program for waste from the commercial nuclear power industry is directed toward the development of two processes for the conversion of the liquid waste to solid silicates. These two fixation processes are being developed and tested in pilot plants and will finally be demonstrated with high-level radioactive waste in a heavily shielded process facility.

One process being developed is the spray solidification-melting process, illustrated in Figure 2. In this process the liquid waste is sprayed into an externally heated drying chamber. The resulting dry, fine powder is separated from process vapors and gases by porous metal filters. The powder is periodically removed from the filters by blowing compressed air backward through the filter. The powder falls into the melter where the 
waste is melted along with added silicate glass. The melt is finally discharged into the waste canister where it is cooled to a solid mass. The canister is then sealed and taken to storage.

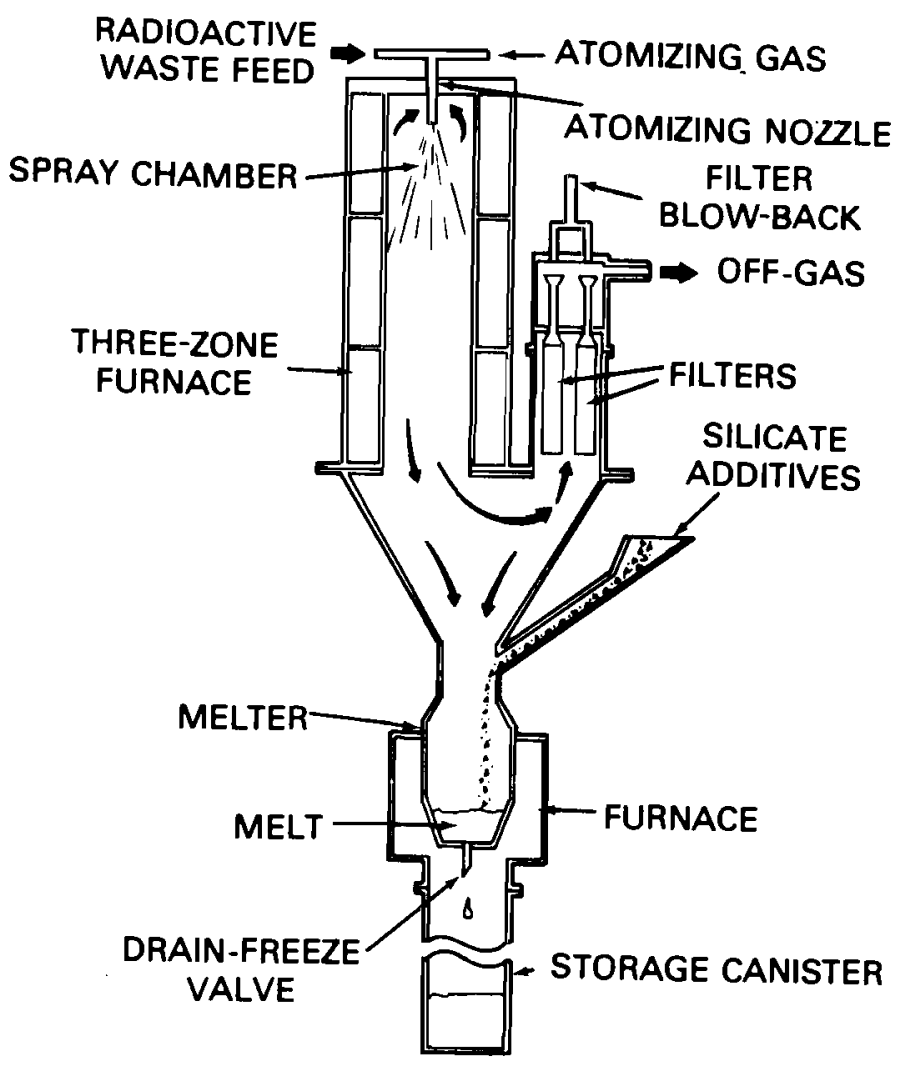

\section{FIGURE 2. Spray Calciner and Continuous Silicate Glass Melter}

The second process, Figure 3, uses a fluidized bed instead of a spray chamber to dry and calcine the waste. The melting step for either process is the same. The heat for the fluidized bed is supplied by burning kerosene with oxygen. The calcine from the fluidized bed is a free-flowing granular solid drawn off from the calciner bed and a fine powder removed from the process off-gases by porous metal filters. This calcine is melted with added silicates and other chemicals and cast into the waste canister, which is then sealed for storage. 


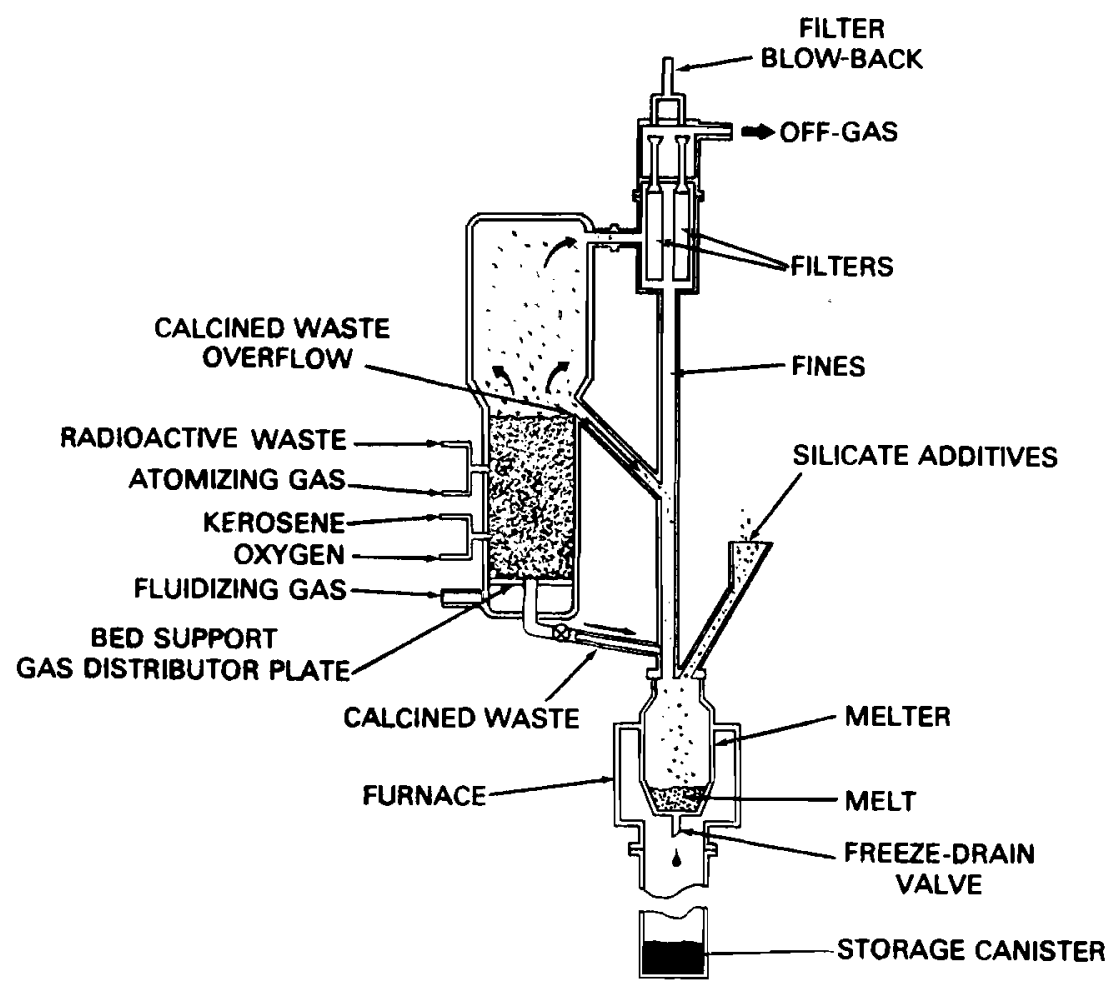

FIGURE 3. Fluidized Bed Calciner and Continuous Silicate Glass Melter

The use of an agitated film evaporator to dewater the waste is also being considered as a first step in the waste solidification process. Plans are to initially test this drying method with nonradioactive solutions which chemically simulate the actual waste.

A parallel effort is being made to develop melter vessels made of both metaliic and ceramic materials. The ceramic melter will be used to form products with melting points above $1200^{\circ} \mathrm{C}$ if such temperatures are necessary to produce materials having superior properties.

The development and evaluation of new and improved solid waste forms are being conducted by testing various silicate compositions, including borosilicates, and by evaluating new waste forms such as ceramics and cermets (a ceramic-metal composite material). 


\section{AEC Waste Studies}

These studies are aimed at the fixation of waste generated from the AEC's plutonium production effort at the Hanford Works, near Richland, washington. The studies are related to similar programs for fixation of waste from the AEC's Savannah River plutonium production site near Aiken, South Carolina. The solid and liquid wastes from these sites have a lower level of radioactivity than commercial reactor waste; but they are voluminous and alkaline, have a variety of compositions and typically contain large amounts of sodium salts. Consequently, the waste fixation processes used must be suitable for large production rates (several million gallons per year of waste) and adequate for drying low melting point sodium salts.

Plans are presently being made to develop a melting process for incorporating certain wastes in a silicate glass and to develop another process for fixing other wastes as crystalline silicates by low temperature reaction with clay minerals. The final process and related equipment selection has not been made, but it probatiy will resemble that used in the largescale industrial production of glass and clay products.

\section{Product Evaluation}

The solid products prepared and developed in waste fixation studies on commercial and AEC wastes will be evaluated using such factors as leachability, volatility, chemical and radiotoxic stability, and mechanical dispersibility. In addition, a radiological evaluation (similar to that described on page 16) will be performed. This evaluation will consider radiological effects as they are influenced by the waste form and composition in various postulated release modes, considering the probability of the release mode occurring. 
ADVANCED CONCEPTS FOR DISPOSAL OF HIGH-LEVEL RADIOACTIVE WASTE 


\section{ADVANCED CONCEPTS FOR DISPOSAL OF HIGH-LEVEL RADIOACTIVE WASTE}

This section describes the various waste management alternatives under study at PNL and outlines the evaluation methods being used.

A list of the basic waste management concepts being evaluated is given below. Additional concepts and variations of listed concepts will be studied as they are identified. As shown, the high-level radioactive waste disposal concepts are divided into two categories: El imination and Earth Disposa1.

\section{Concepts Under Study for High-Leve 1}

Radioactive Waste Management

\section{Elimination}

Transmutation

Accelerator

Fission Reactor

Controlled Thermonuclear Reactor

Extraterrestrial

Solar Impact

Orbiting

Solar Escape to Deep Space
Earth Disposal

Geologic Formations

Mined Cavity Nuclear Cavity

Deep Hole Drilled Hole Matrix Manmade Structures in Geologic Formations

Seabed

Rapid Sedimentation Burial Deep Trenches

Tectonic Subsidence Areas

Stable Deep Sea Floor

Ice Sheet

Ice Burial - Free Flow

Ice Burial - Anchored

Ice Surface Facility 
For each waste management alternative under investigation the following tasks are being completed:

\section{Investigation Objectives for Each Waste Management Alternative}

Compile and Evaluate:

- Technical and Safety Feasibility Information

- Policy, Environmental, and Public Acceptance Considerations

- Advantages and Disadvantages

Develop:

- Estimate of Needed Research and Development

- Estimate of Schedules and Capital and Operating Costs

In support of these evaluations studies are being conducted in the following areas:

Radiological Evaluations - A study of possible "pathways for radionuclides in waste to contact man" assuming primary waste containment fails for the waste management concepts under evaluation.

Waste Partitioning - A study of the benefits of and means for separating radionuclides in waste into various component fractions (such as a fraction of transuranic radionuclides and all other radionuclides before disposal, storage, or elimination).

A logic diagram showing potential routes of nuclear wastes from discharge of reactor fuel (the source of the waste) through the ultimate waste management method used for final disposition is shown in Figure 4. 


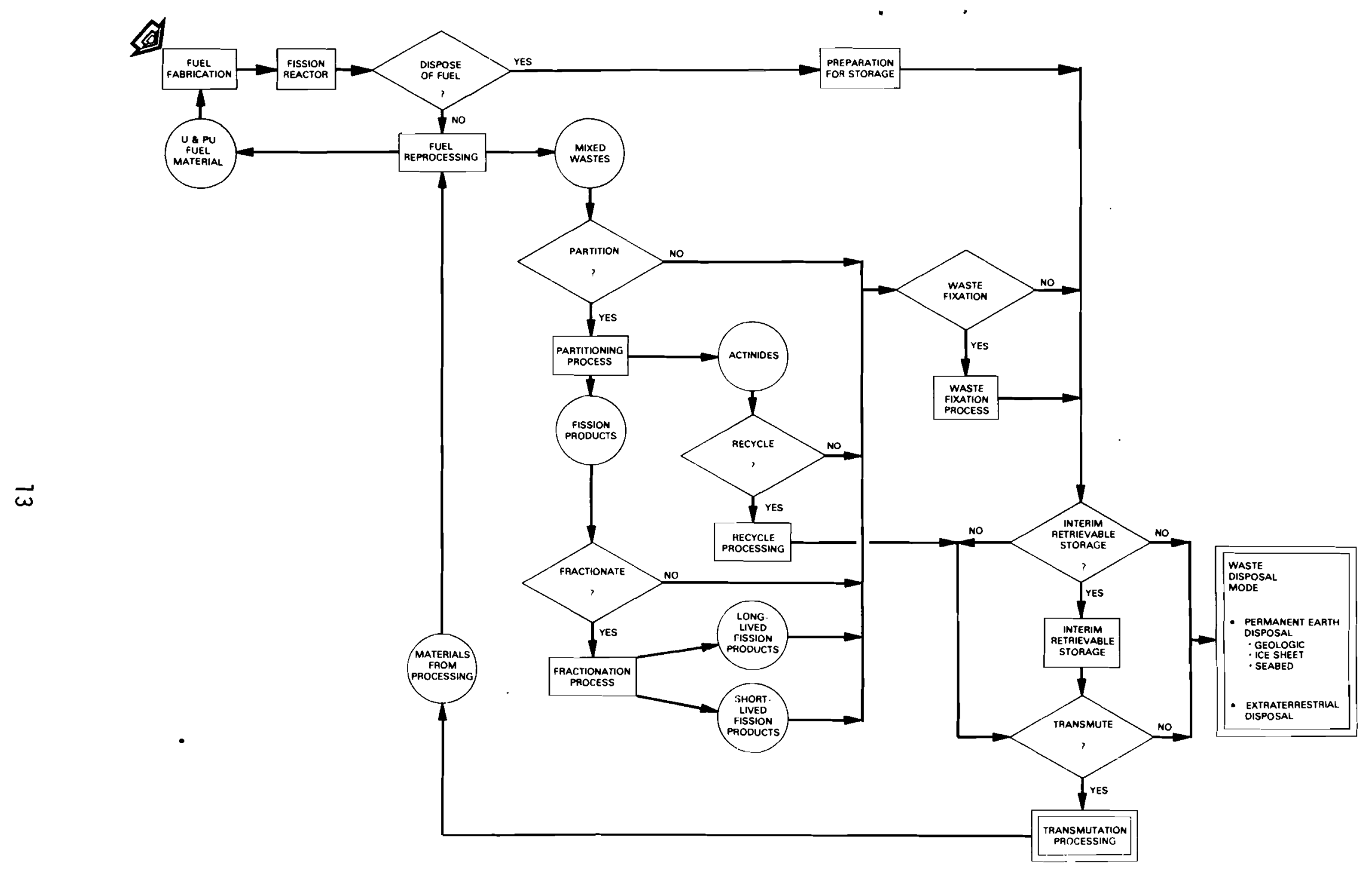

FIGURE 4. Was te Management Logic Diagram 


\section{Evaluation Factors}

Numerous evaluation factors are being applied to each of the many possible waste management concepts being studied. The objective is to systematically develop information on each concept which can then be used to provide a basis for recommendations and decisions on high-level waste management alternatives. The evaluation facturs being emphasized are discussed below and the relationship between these factors is shown in Figure 5.

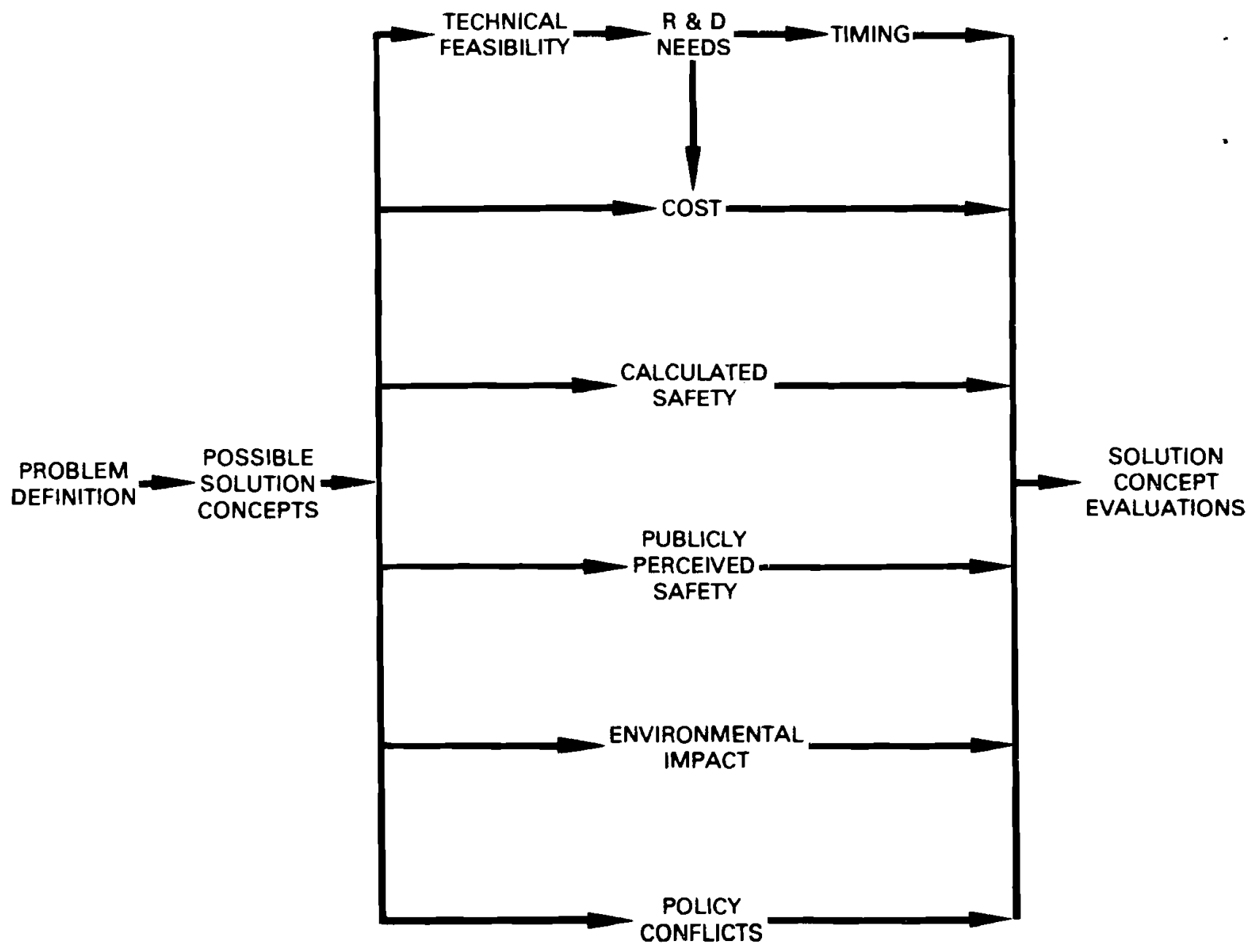

FIGURE 5. Relationships Between Evaluation Factors 
Technical Feasibility

Each alternative for waste management is analyzed in terms of its technical feasibility. This analysis is based on three primary considerations:

- The feasibility of implementing the concept and assuring waste containment over the needed time period in light of presently available data

- The energy balance involved in the process (i.e., any system which requires more energy to dispose of the waste than was generated from the original nuclear fuel is clearly eliminated)

- Major research and development needs: The major problem areas identified while studying the technical feasibility of each concept are analyzed in further detail to delineate the overall scope of needed research and development. Estimates are made for the time period required and the research and development expenditures per year necessary for the solution of each problem.

$\underline{\text { Timing }}$

The purpose of this factor is to estimate the earliest reasonable date a given alternative could be in commercial operation. $\underline{\text { Costs }}$

The discounted capital and operating costs of the alternatives are summed over the time period of concern for the study. The costs of any waste partitioning or other processing requirements are included.

Policy

Any aspect of a permanent disposal option in conflict with existing policy is identified. National or international policy changes which would be required to make a given process allowable are indicated. Safety

Features of each concept which relate to its safe use are identified and evaluated. A radiological evaluation (described in the next section) 
is included in the safety analysis. A committee of experts reviews the safety analyses for each concept. This committee advises on the techniques to be used, the data sources, and the data to be developed to allow the calculation of the risk to the populace for each alternative.

Perceived Safety (Public Acceptance)

Another cormittee includes experts in social psychology. These people identify the elements of safety which make certain risks more acceptable to the public than other risks. They will help design methods of communicating real or calculated risks to the general public.

\section{Environmental Impact}

The overall impact of each concept on the environment is evaluated. The data which must be developed on such criteria as land use, water use, and effects on plant and animal life is defined.

\section{Radiological Evaluation}

Exposure of humans to radioactive materials from high-level waste, either from external sources or from internally-deposited radionuclides, involves some risk of physiological effect. Evaluation of this risk, however sma11, requires estimation of the total radiation dose received by man from all significant pathways. Such estimates are being made and used to evaluate and compare the relative risks associated with alternative disposal concepts. Such estimates also provide guidance on priorities for development of additional waste fixation and waste separation processes to assist in reducing potential exposures from individual radionuclides. Overall risk evaluation will include an assessment of probabilities that a postulated series of events, determined from analysis of potential concept failure mechanisms, may result in the introduction of specific radionuclides into man's immediate environment.

Figure 6 illustrates the variety of radiation exposure pathways and the many factors which enter into the eventual dose estimates. Figure 7 shows the interrelation between pathway to man, risk to man and probability of occurrence. 


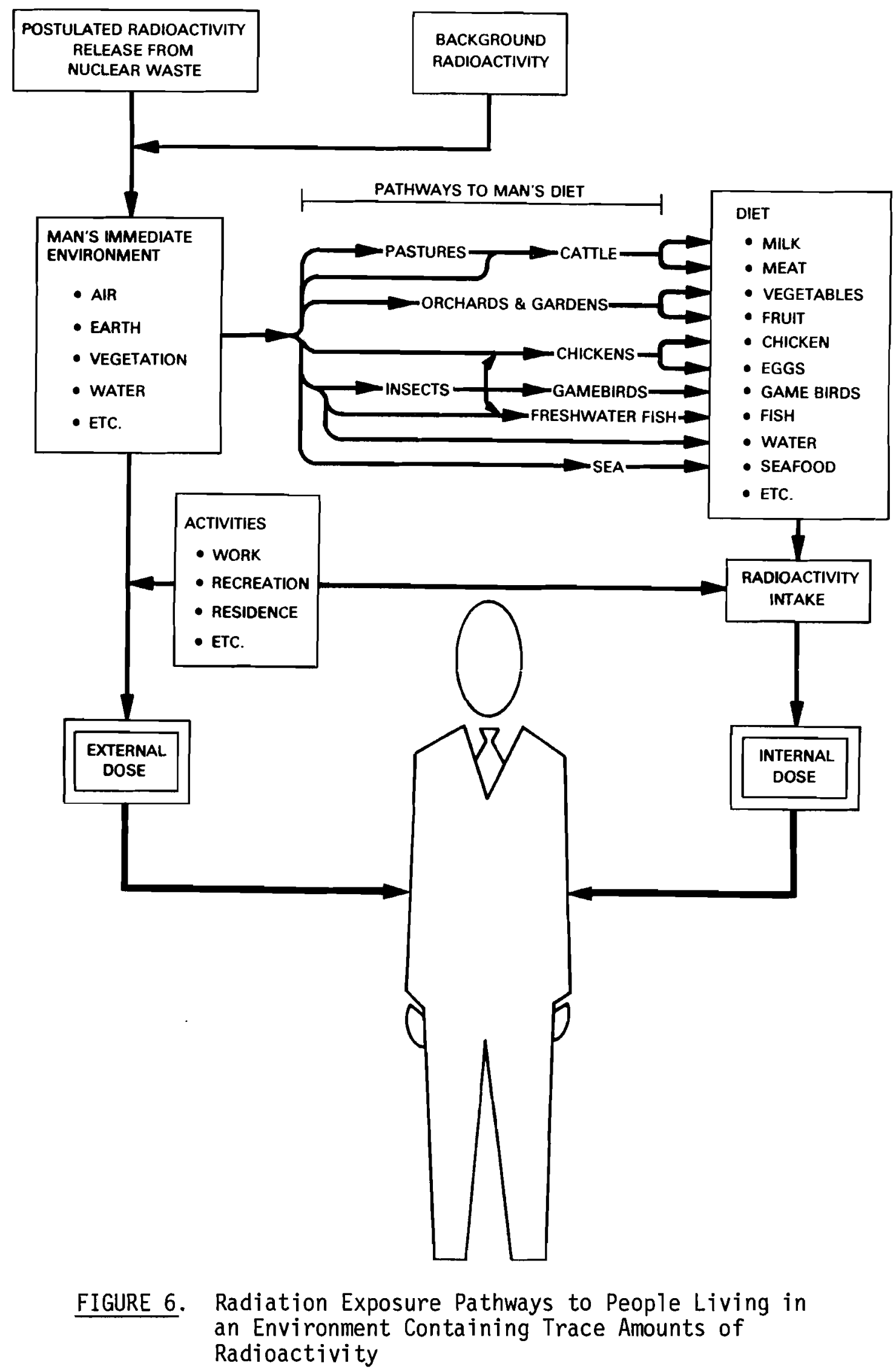




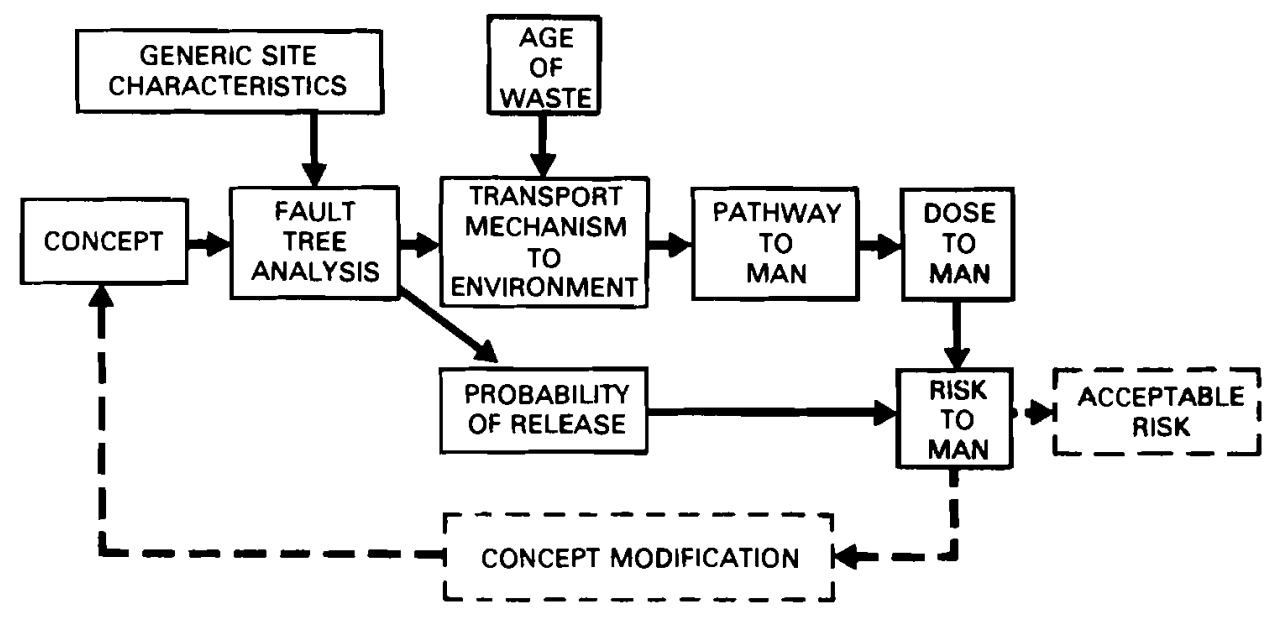

FIGURE 7. Interrelation Between Pathway, Probability and Risk

\section{Geologic Disposal}

Disposal of radioactive waste in geologic formations has the potential of isolating the waste from man's environment for extended time periods (millions of years). Geologic environments exist which have been physically and chemically stable for millions of years, are isolated from man's environment, and can potentially provide effective barriers between waste and man's environment for the time periods required. The basic requirement for any geologic environment to be suitable for disposal of radioactive waste is the capability to safely contain the emplaced radioactive material until decay has reduced the radioactivity to nonhazardous levels. The geologic environment should a) be adequately far removed from man's environment, b) not permit was te transport readily, c) remain relatively stable over geologic time periods, and d) adequately contain a highly immobile waste form.

There are several ways a geologic formation can be penetrated and altered to provide a suitable cavity for waste emplacement purposes. The present study is considering the use of drilling, mining (mechanical and dissolution), hydraulic fracturing, and nuclear cavity formation. A11 of these methods become more difficult with increasing depth. At 
depths up to about 3 kilometers any of the methods may be used. Drilling has the potential of going to great depths; the present record is around 9 kilometers (about 5.6 miles).

The geologic disposal studies being performed by PNL involve evaluation of concepts other than the bedded salt disposal concept which is under study for the U.S. Atomic Energy Commission at the Oak Ridge National Laboratory. The methods under consideration by PNL for disposal of radioactive waste in a given geologic formation include:

- Placing solidified waste directly in a geologic formation

- Placing solidified waste in manmade containment barriers within a geologic formation

- Placing solidified waste in a geologic formation in a configuration to allow the waste to melt and form a rock-waste matrix

- Converting liquid waste in-place within a geologic formation to form a solid waste or a rock-waste matrix.

Each of these basic concepts has a number of variations. An example of each concept is shown in Figures 8 through 11.

Disposal of previously solidified waste in a conventionally mined cavity, shown in Figure 8, is one of the more basic concepts under study. This concept is similar to that proposed. for the pilot plant repository in a bedded salt deposit. This concept would use a building above ground to receive the waste canisters and transfer them down into the underground area. A network of cavities underground would be filled with waste in such a manner that the heat is transferred directly to the host rock formation. The individual holes for the waste canisters would be back-filled at the time of waste placement. Eventually the entire mined system would be permanently sealed. 


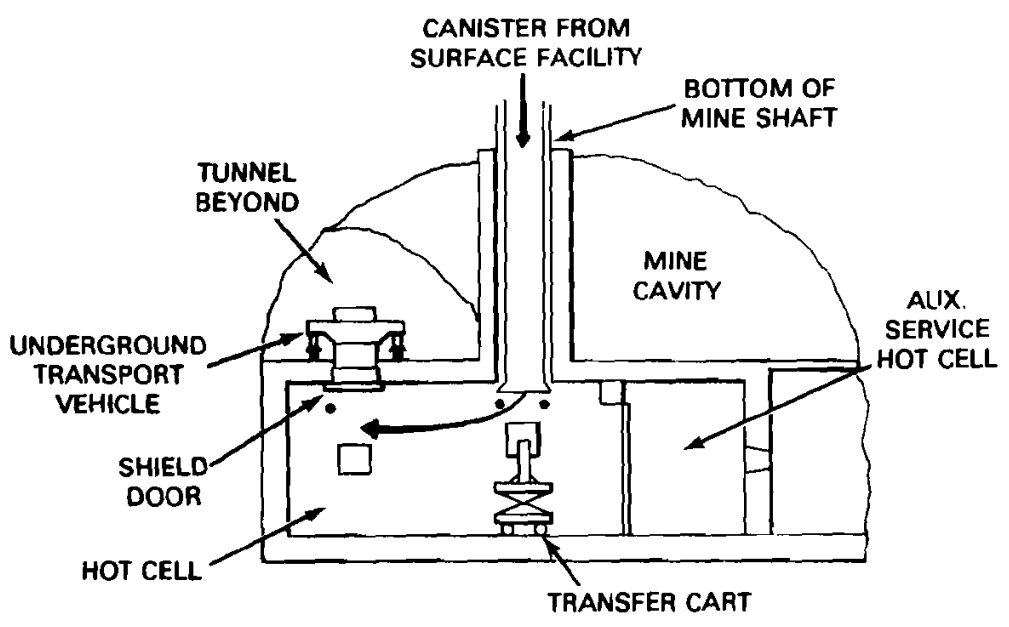

SECTIONAL ELEVATION THROUGH SUB-SURFACE HANDLING FACILITY

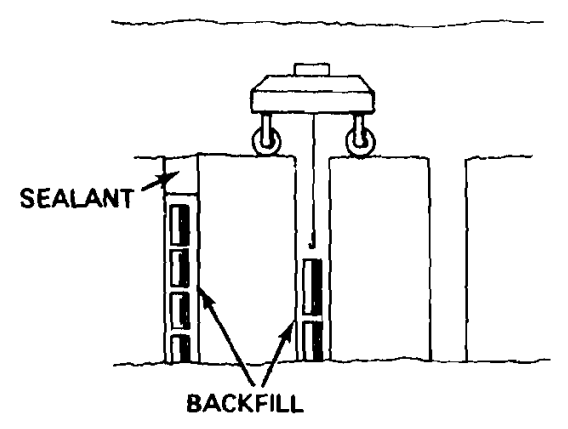

SECTIONAL ELEVATIONPLACEMENT OF WASTE IN FLOOR OF MINED ROOM

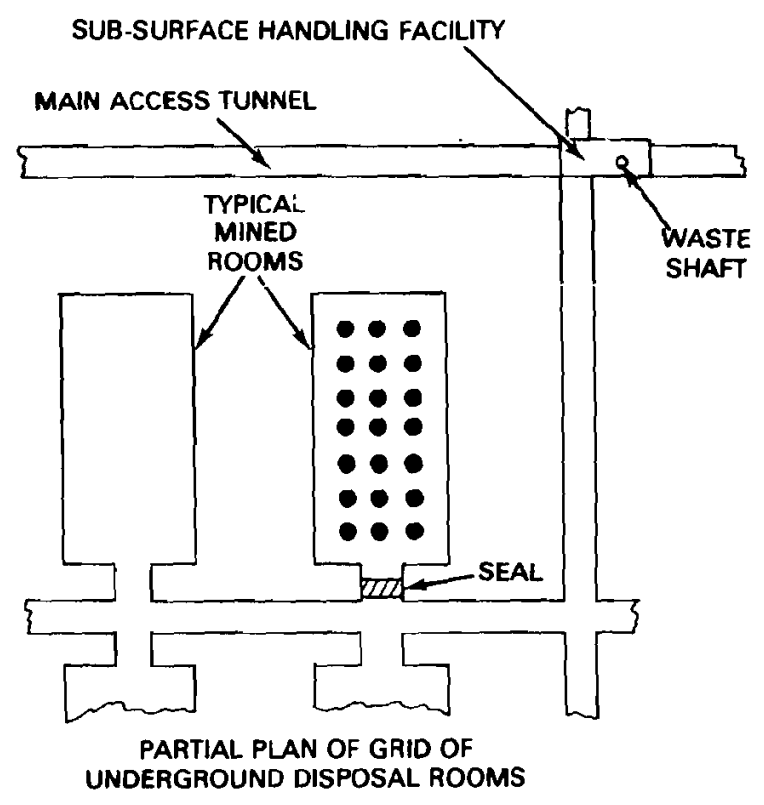

FIGURE 8. Solidified Waste in Mined Cavity 
OUTLET FILTERS

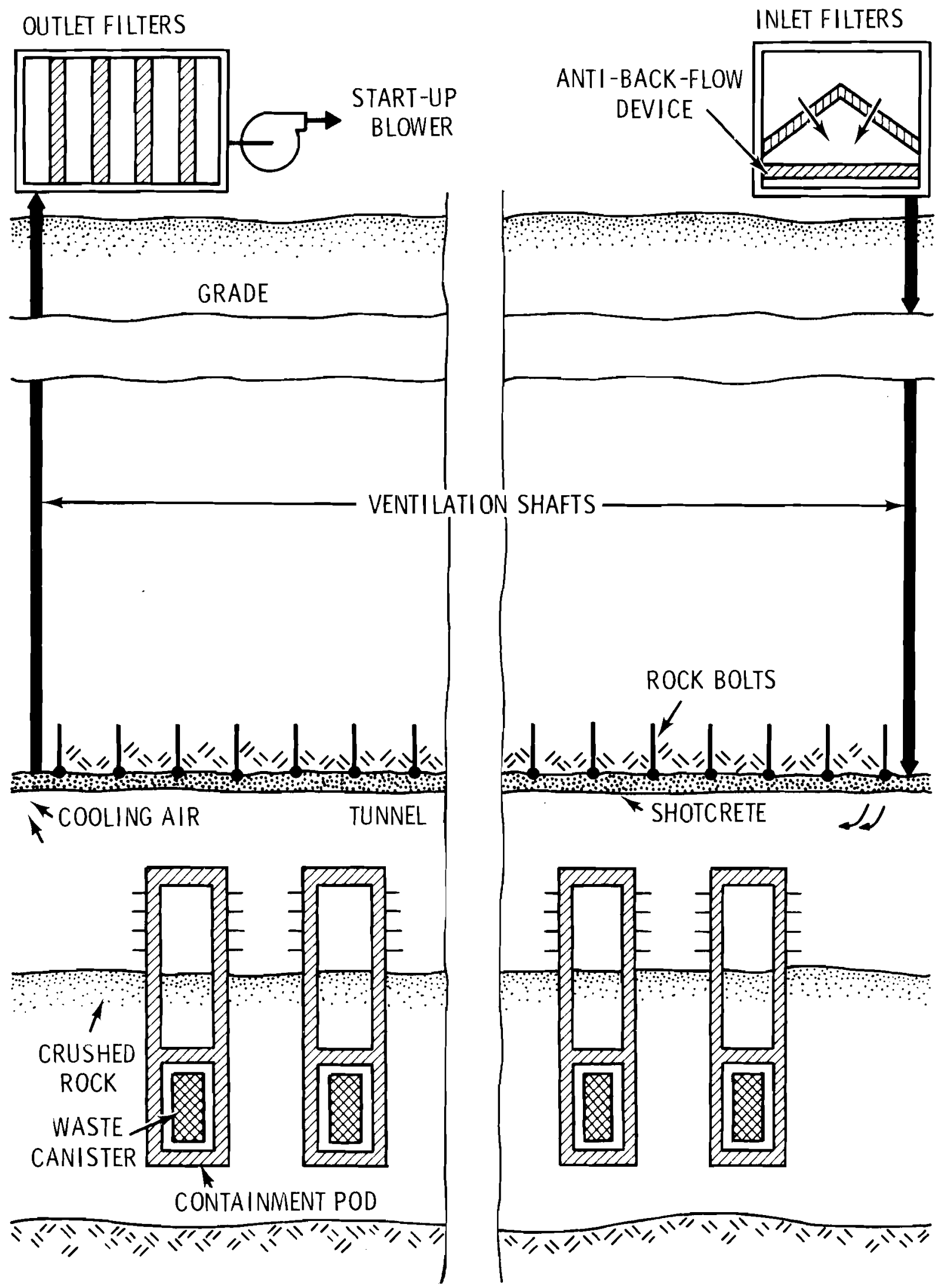

FIGURE 9. Concept for Solid Waste Emplacement in a Mined Tunnel with Natural Convection Air Cooling 


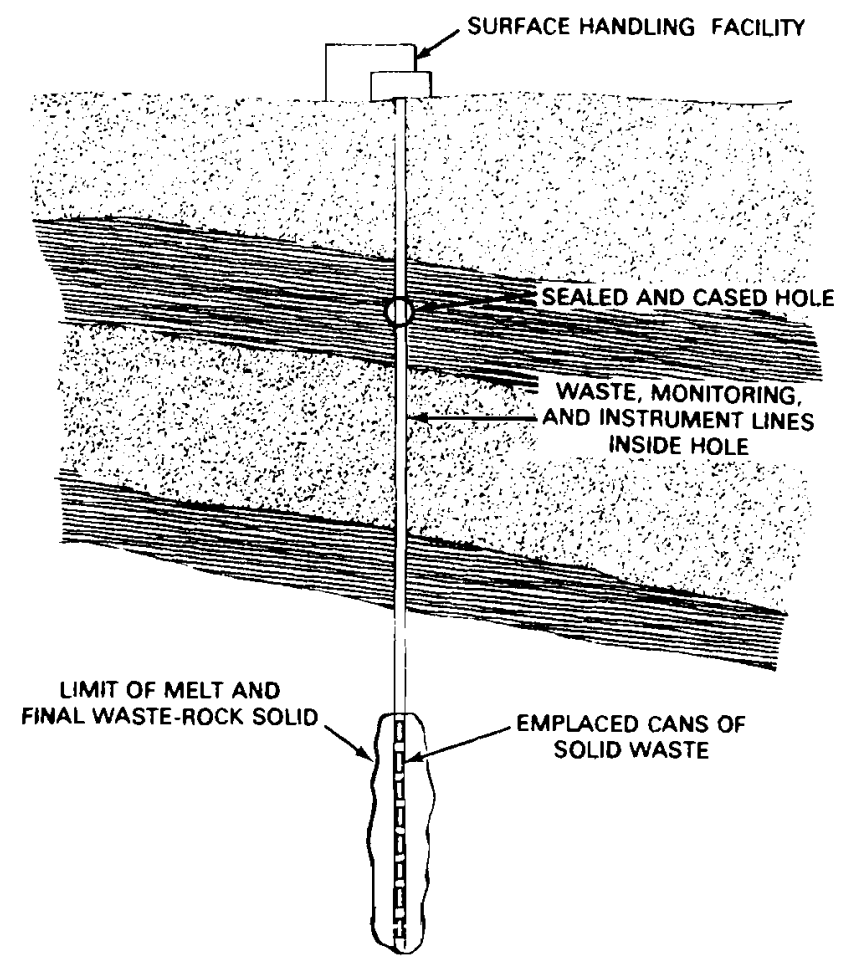

FIGURE 10. Deep Drilled Hole Concept, Solid Emplacement, In-Place Conversion to Rock-Waste Matrix

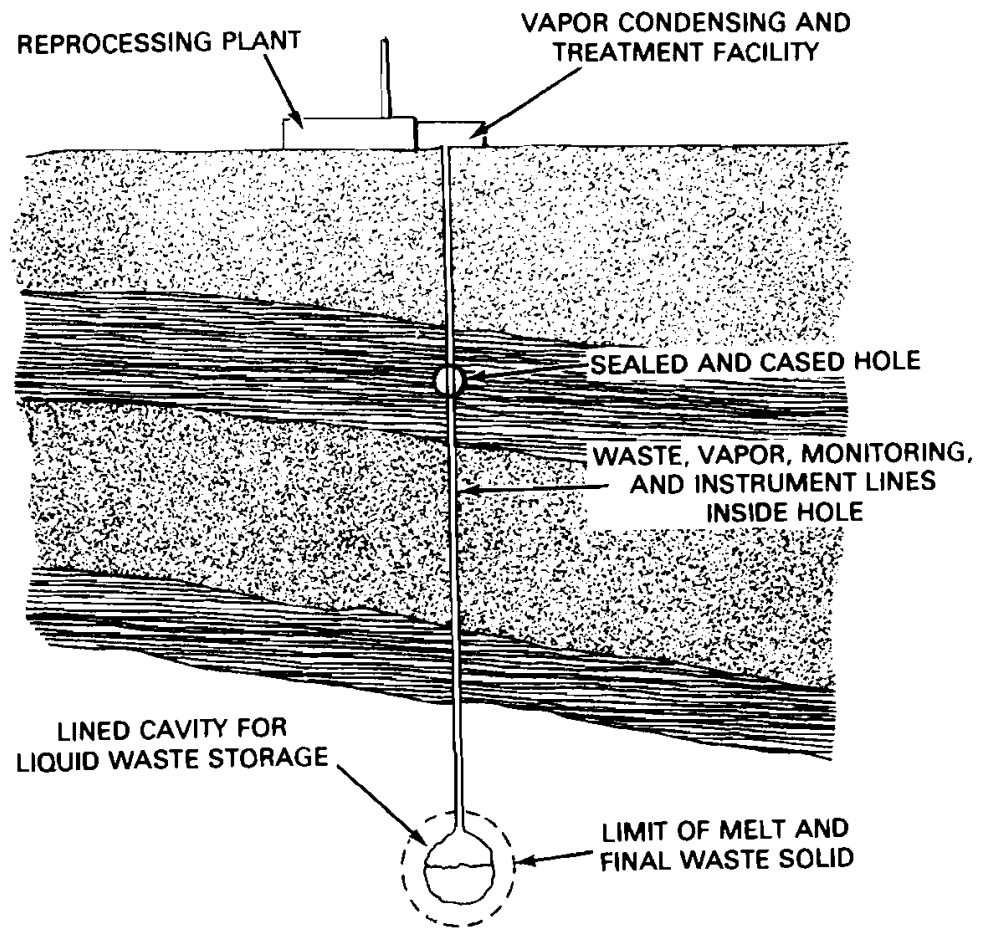

FIGURE 11. Mined Cavity Concept, Liquid Emplacement, In-Place Solidification 
As shown in Figure 9, manmade containment barriers within geologic formations can be used to allow waste retrievability for a limited time period (about 100 years). They can also provide one or more additional barriers for release of radioactive waste constituents into man's environment. The concept shown in Figure 9 requires surface handling facilities similar to the previous concept. However, here the waste canisters are placed in storage pods located in lined tunnels. The storage pods are air cooled. Other means of cooling could also be used. After an appropriate time period (generally tens of years), the cooling system can be shut down and the repository permanently sealed.

Figure 10 shows a concept where solidified and containerized waste is placed in deep drilled holes, allowed to self-heat and melt itself and some of the surrounding rock. Eventually the melt cools and solidifies to a rock-waste matrix. After addition of waste the holes are sealed. These drilled holes might be very deep (i.e., 10 miles or 16 kilometers) if such deep locations are shown to provide significant additional safety. Concepts such as these generaliy require significantly smaller cavity volumes than mined cavities. Theoretically, the chemistry of the solidified waste can be tailored to be compatible with the surrounding rock, with the final rock-waste matrix being a durable solid. Variations to this concept could involve the use of mined cavities and/or the interim use of artificial cooling.

The fourth basic concept for geologic waste disposal, shown in Figure 11, involves piping liquid waste from the fuel reprocessing plant into a lined mined cavity (equivalent to an underground liquid storage tank). The waste is kept as a boiling liquid by condensing the steam in a surface facility and returning the condensed water to the storage cavity. At a predetermined time steam condensation is discontinued and the self-heating waste is allowed to boil to dryness. The cavity is then sealed and the waste continues heating to become molten 
and then melts the cavity liner and surrounding rock. Eventually the molten materials cool and solidify to a rock-waste matrix. In this concept, the fuel reprocessing plant is located at its own disposal site, thereby eliminating cross-country transport of the waste. Variations of this concept include the use of unlined rubble-filled cavities made by nuclear explosives, the use of drilled holes instead of cavities, and the injection of a self-curing liquid waste slurry into a rock formation previously fractured (hydraulic fracturing).

\section{Seabed Disposal}

Disposal of radioactive waste within the floors of the world's oceans offers a number of possibilities for permanent isolation of the waste from man's environment. Since radioactive waste disposal is a multinational problem, consideration of "common territory" for solving the problem on an international basis appears to have subjective merit. The depth to the floor or seabed would provide isolation and safety from natural disasters such as storms, as well as from sabotage or accidental disturbance. The large volume of seawater could help cool the waste and effectively dilute any material that escaped from the disposal site. The known high ion exchange capacity of the seabed sediments would aid in immobilizing waste material if any waste escape should occur.

The radioactive waste would be in a solid form and enclosed in a durable sealed canister. To further isolate wastes, the canisters would be placed in prepared holes in the seabed, after which the holes would be sealed. The depth of the prepared holes would depend on the nature of the seabed at the disposal site.

Four basic concepts for the seabed disposal of high-level radioactive wastes are being considered, based on the type of seabed area (see Figures 1216). 
- Placement in subductive trench zones (about 10 kilometers below sea level) at margins of certain crustal plates, allowing the waste to be transported into the lower crustal zone of the earth by either underthrusting or sinking of oceanic plates under continental plates

- Placement below the sediments in deep ocean trenches in areas of postulated seabed subsidence (about 7 to $10 \mathrm{kilometers} \mathrm{below} \mathrm{sea}$ leve1)

- Placement below the sediments in stable deep sea floor areas (about 4 to 6 kilometers below sea level), such as abyssal plains or at the base of seamounts

- Placement in sea floor areas where there are high sedimentation rates, such as river deltas, resulting in relatively rapid additional imbedment of high-level wastes.

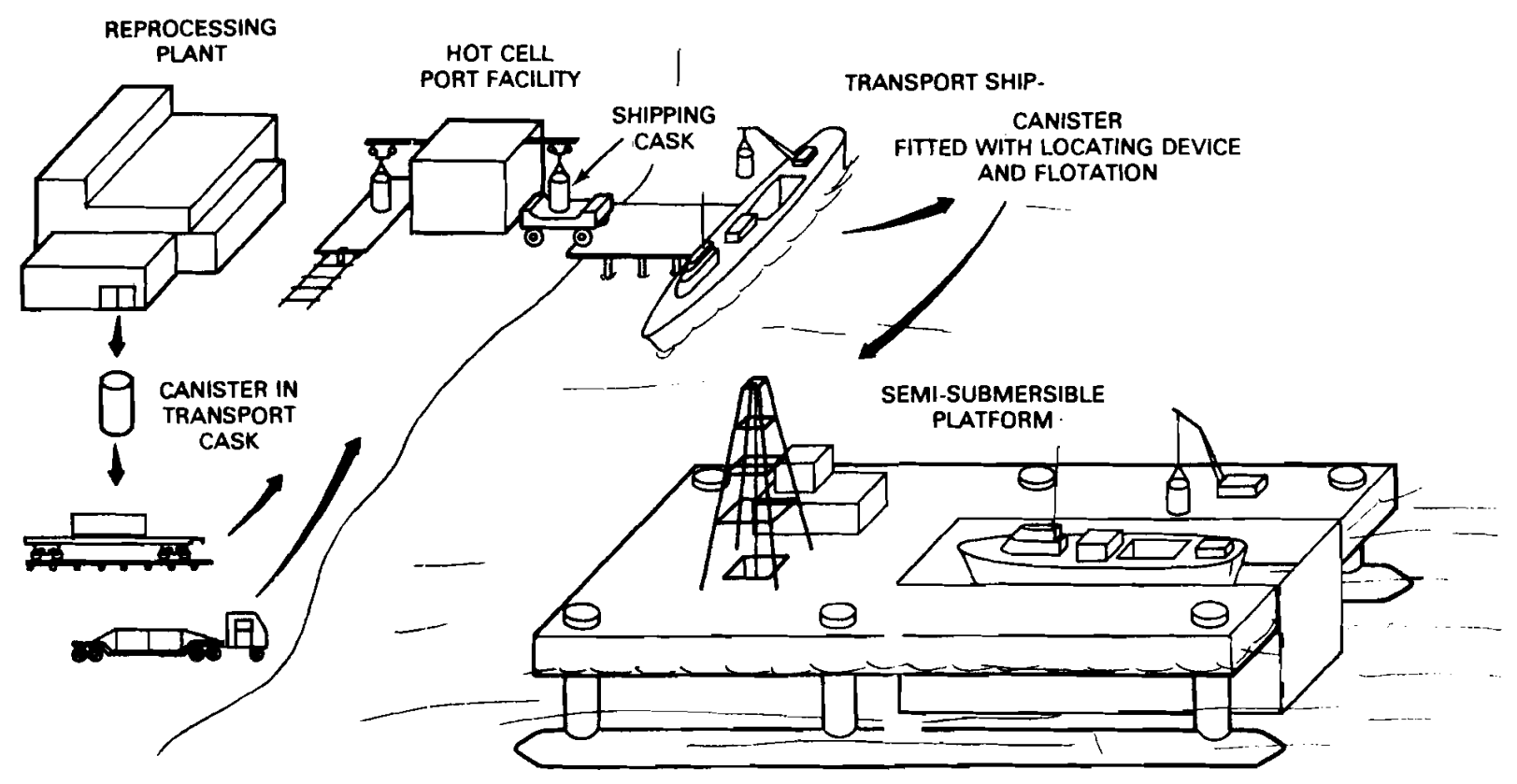

FIGURE 12. Operations in Seabed Disposal 

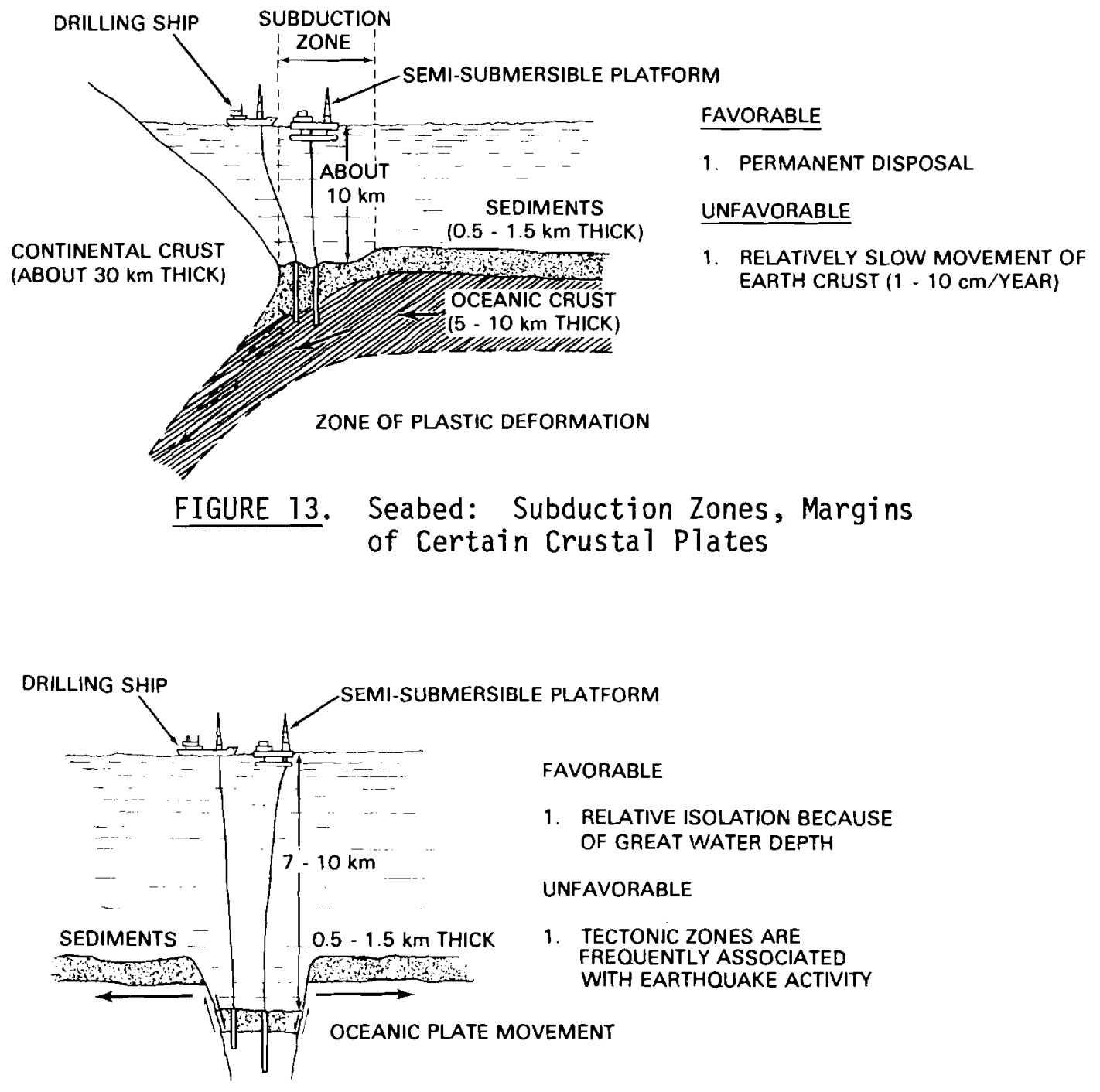

FIGURE 14. Seabed: Deep Trenches

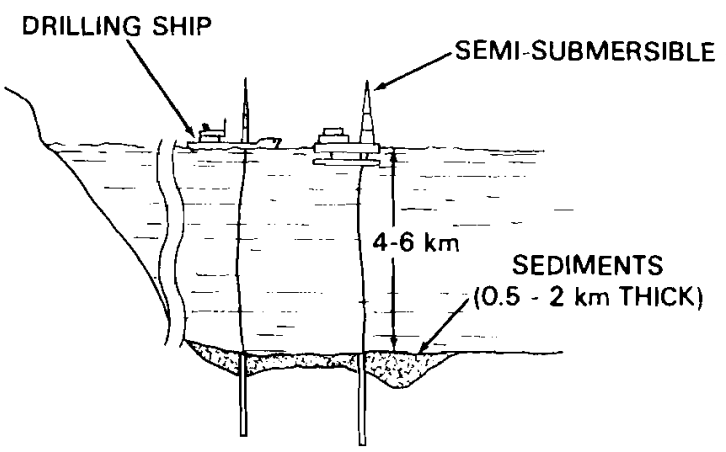

LATFORM

FAVORABLE

1. RELATIVELY STABLE GEOLOGIC SETTING

UNFAVORABLE

1. GENERALLY LOW SEDIMENTATION RATE AND SLOW BURIAL

ABYSSAL PLAIN

\section{FIGURE 15. Seabed: Stable Deep Sea Floor}




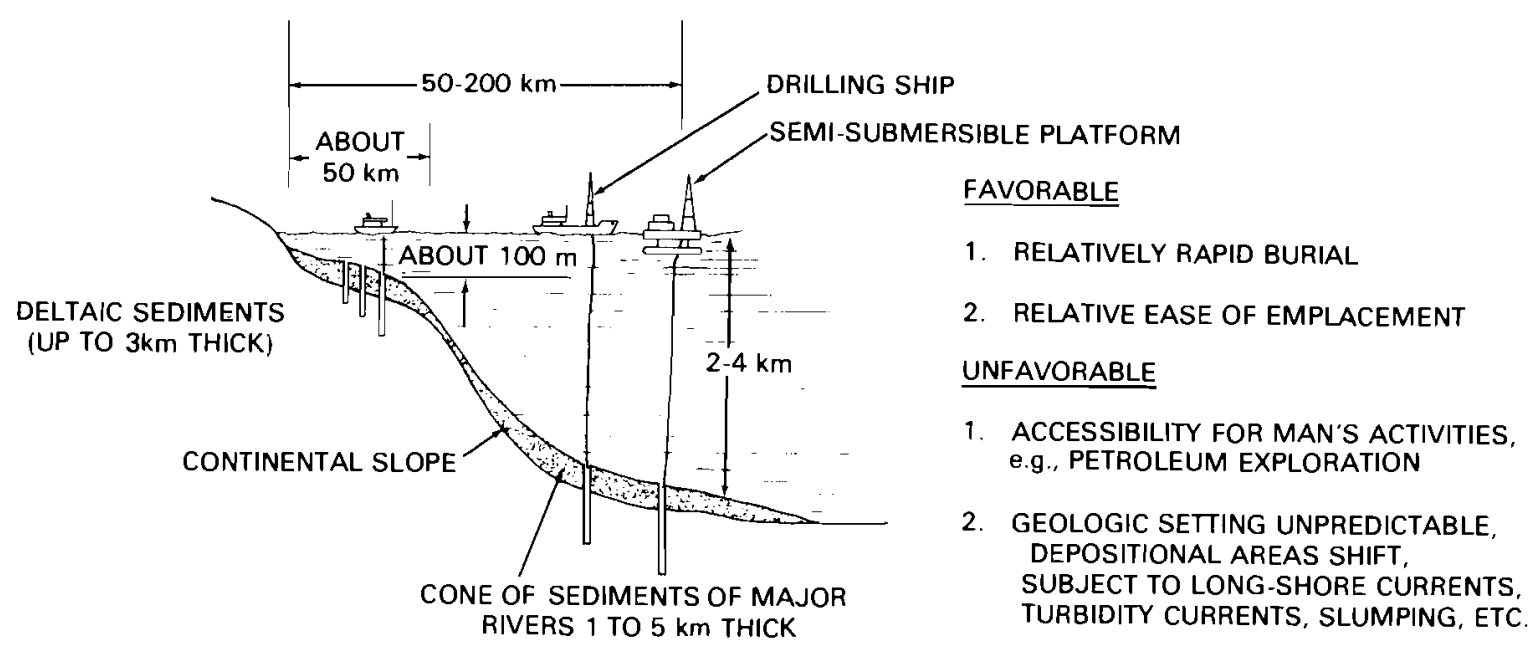

\section{FIGURE 16. Seabed: High Sedimentation Rate Areas}

Factors being considered in PNL investigations include:

- Behavior (1ife expectancy) of waste canisters in their environment within the sea floor

- Mobility of the deep ocean water and sea floor sediments relative to other geologic disposal al ternatives

- Retrieval in the event of unforeseen system failure

- Monitoring disposal system performance

- Means of obtaining information necessary to achieve the desired level of confidence in safety

- Public (including international) acceptance and need for modifying existing international conventions relating to the Law of the Seas.

\section{Ice Sheet Disposal}

Alternative concepts for radioactive waste disposal in the major ice sheets of the world (Greenland and Antarctica) are being evaluated. Potential advantages are great thicknesses of ice, remoteness from man's activities and low likelihood for future development. The ice could provide effective direct cooling for the waste and, at the same time, maintain isolation from man's environment. The following concepts are under study: 
- Direct placement of packaged waste on or just below the surface with subsequent self-meltdown through the ice

- Direct placement of packaged waste just below the ice surface, but with anchors at the surface to maintain the waste canister at a selected depth in the ice for a limited time period

- Placement of packaged waste in manmade structural facilities on the surface of the ice.

The operations involved with these concepts are shown in Figure 17 and the concepts themselves are shown in Figures 18 through 20.

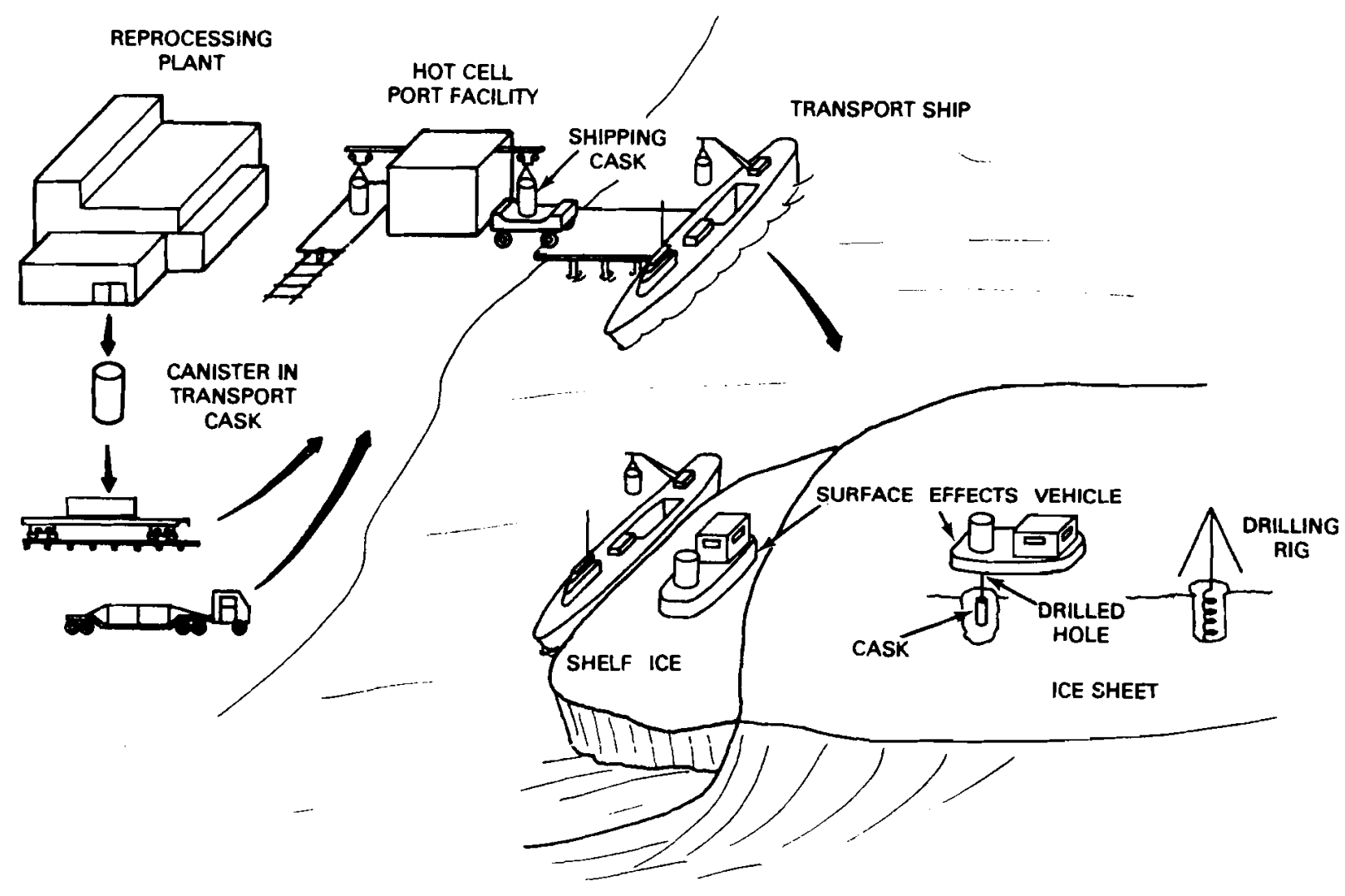

FIGURE 17. Operations in Ice Sheet Disposal 


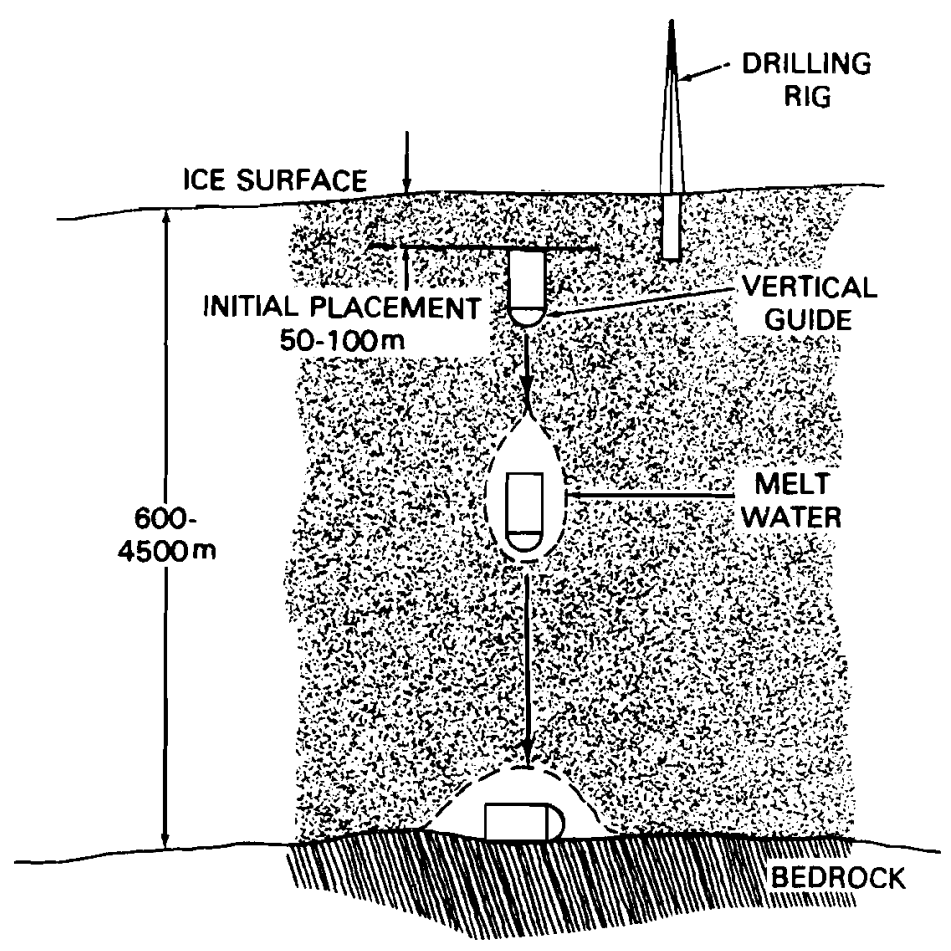

FAVORABLE:

1. SELF-EMPLACEMENT

2. SAFE FROM STORMS, SABOTAGE, ETC.

3. FINAL DISPOSITION (5-10 YEARS)

UNFAVORABLE:

1. DIFFICULT TO MONITOR

2. DIFFICULT TO RETRIEVE

3. LACK OF KNOWLEDGE OF MEDIUM MOBILITY, PARTICULARLY NEAR BEDROCK

FIGURE 18. Ice Sheet: Free Flow Waste Canister Melts Down to Bedrock

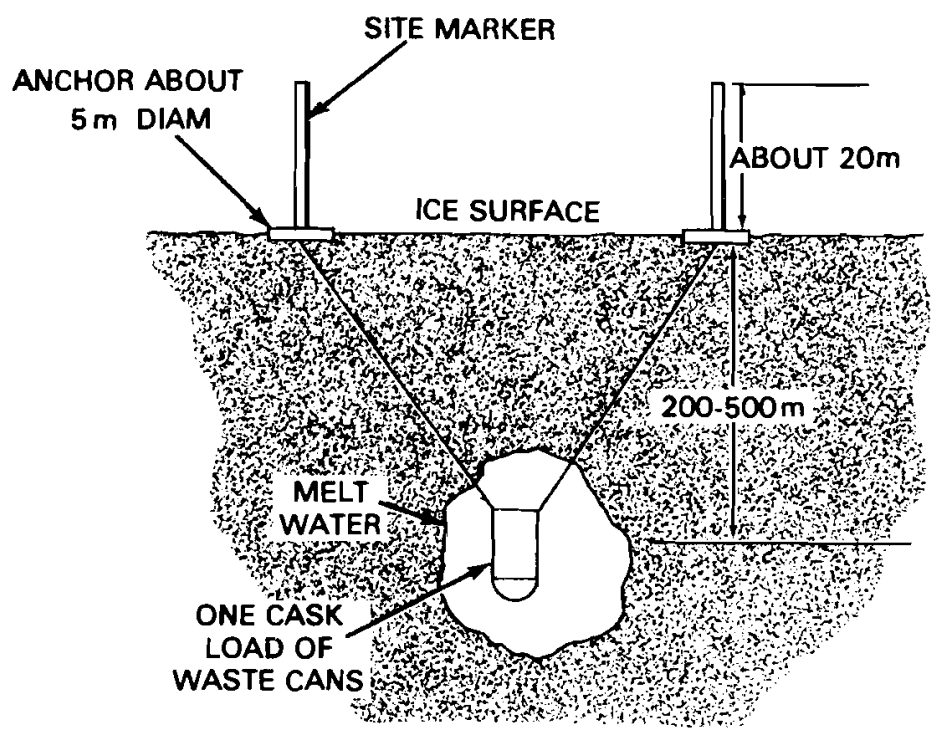

\section{FAVORABLE:}

1. SELF-EMPLACEMENT

2. LIMITED MONITORABILITY (20-100 YEARS)

3. LIMITED RETRIEVABII_ITY (20-100 YEARS)

4. LIMITED LOCATABILITY (100-200 YEARS)

UNFAVORABLE:

1. SYSTEM WILL EVENTUALLY SINK/BE COVERED

2. MELT CAVITY MAY MIGRATE TOWARD SURFACE

FIGURE 19. Ice Sheet: Anchored Storage, Predetermined Depth 


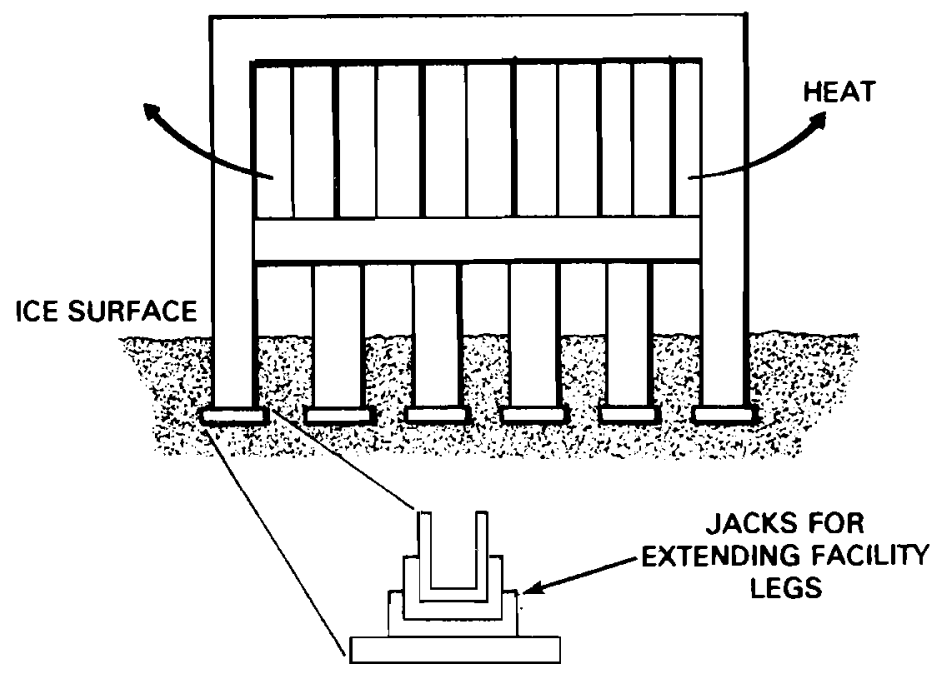

\section{FAVORABLE:}

1. HIGH MONITORABILITY (UP TO 50 YEARS)

2. EASE OF RETRIEVABILITY (UP TO 50 YEARS)

3. LOCATION KNOWN (UP TO 50 YEARS)

\section{UNFAVORABLE:}

1. EXPOSURE TO STORMS SABOTAGE, ETC.

2. TENDENCY TO SINK/BE BURIED IS UNCONTROLLED

3. POOR ISOLATION FROM ENVIRONMENT IF FACILITY IS DAMAGED OR DESTROYED

FIGURE 20. Ice Sheet: Surface Storage Facility

The radioactive waste should be in solid form and encased in durable sealed canisters. The canisters could be placed in shallow drilled holes and allowed to melt their way downward, either to the bottom of the ice or to a specified depth within the ice. The melted ice would refreeze as the canister descended, sealing the wastes within the ice. A surface storage facility might also be used in which the waste was stored in a secure structure on the surface of the ice. This method offers the advantage of ready surveillance in addition to remoteness and isolation.

Several factors have been identified for investigation. A multinational treaty presently exists, prohibiting waste disposal in Antarctica where the largest and thickest ice mass is located. In addition to this, transportation costs, logistics, the short operating season, and waste monitoring and maintenance factors would have to be considered. Definite knowledge about subsurface ice movement and about conditions near the bottom of the ice mass is also needed.

\section{Extraterrestrial Disposal}

Disposal of nuclear reactor waste by removing it from the earth with rockets is being evaluated with assistance from the technical staff at the 
NASA-Lewis Research Center, Cleveland, Ohio. One of the principal potential advantages to this concept is that it removes undesirable elements from the earth and does not leave a potential terrestrial problem for future generations. However, to make the concept economically feasible it may be necessary to dispose of only transuranic radioactive by-products* extraterrestrially, removing them from the high-level waste using suitable separations processes (waste partitioning).

Containment capsules which provide reasonable safety in the event of a launch abort or an earth re-entry situation have been demonstrated for nuclear heat sources in AEC programs, oriented toward NASA applications. Such heaters have been deployed in power supply systems placed on the moon in several manned lunar missions. Based on this experience, a conceptual waste containment capsule design was developed (Figure 21) and the economics of encapsulation seem reasonable.

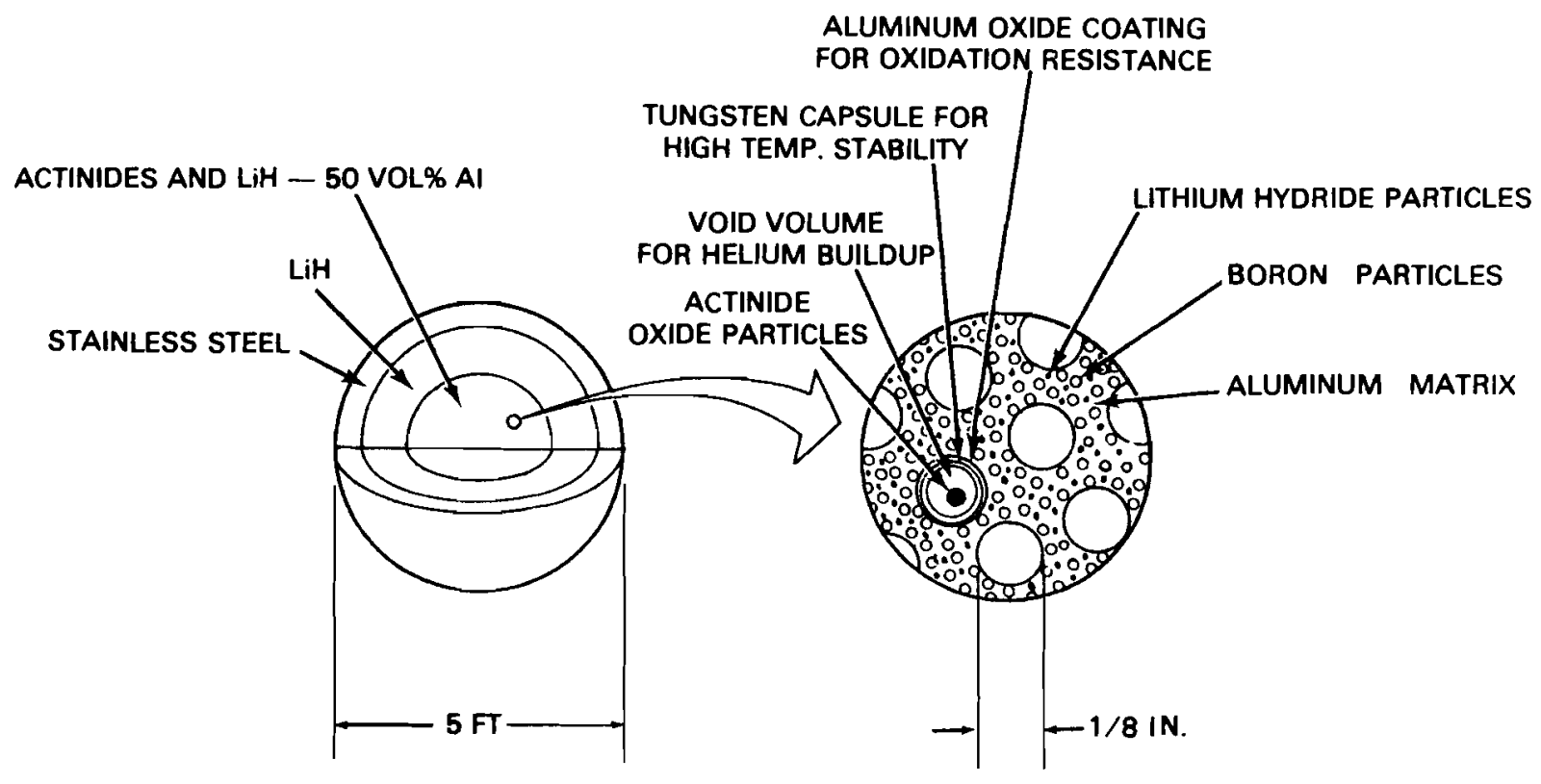

FIGURE 21. Extraterrestrial Waste Encapsulation and Containment Concept

* Isotopes of $\mathrm{Np}, \mathrm{Am}, \mathrm{Cm}$, and $\mathrm{Pu}$. 
Several possible flight trajectories and destinations are being investigated. Listed in order of increasing escape velocity required, they include trajectories leading to high earth orbit, solar orbit, escape from the solar system to deep space, and impact on the sun. Escape velocity information and current space vehicle capabilities are summarized in Figure 22. Other destinations, such as storage on the moon, are also being examined. Two trajectories which offer the most likelihood of final disposal are solar impact and solar escape. With solar impact, which is difficult with present vehicles, there is some possibility that some atoms could be carried by the solar wind back into the path of the earth. In this case dilution is expected to be great enough that waste material finally intercepted by the earth could be undetectable, but this is being investigated further.

With solar escape, current knowledge indicates that there would be no possibility of return to earth once an escape trajectory is assured. Current knowledge also shows there is little probability of adversely affecting other beings in outer space, since it would require over a million years for a waste package to reach the nearest star. However, if new knowledge is acquired in future years, or if new circumstances change the present conclusions, recovery of material enroute to deep space would be extremely difficult.

Vehicles used in the analyses include existing space vehicles and the planned space shuttle and tugs. A shuttle-tug combination is illustrated in Figure 23. The space shuttle launch vehicle is assisted at lift-off by two solid-fueled rocket motors. After firing, these are separated and dropped into the ocean where they are recovered. After use, the expendable external propellent tank is separated from the orbiter and then de-orbited by a small retro-rocket. The tug, with the waste payload, is deployed from the payload bay of the orbiter. For escape from the solar system, a second tug is required, so two space shuttle launches must be made. 


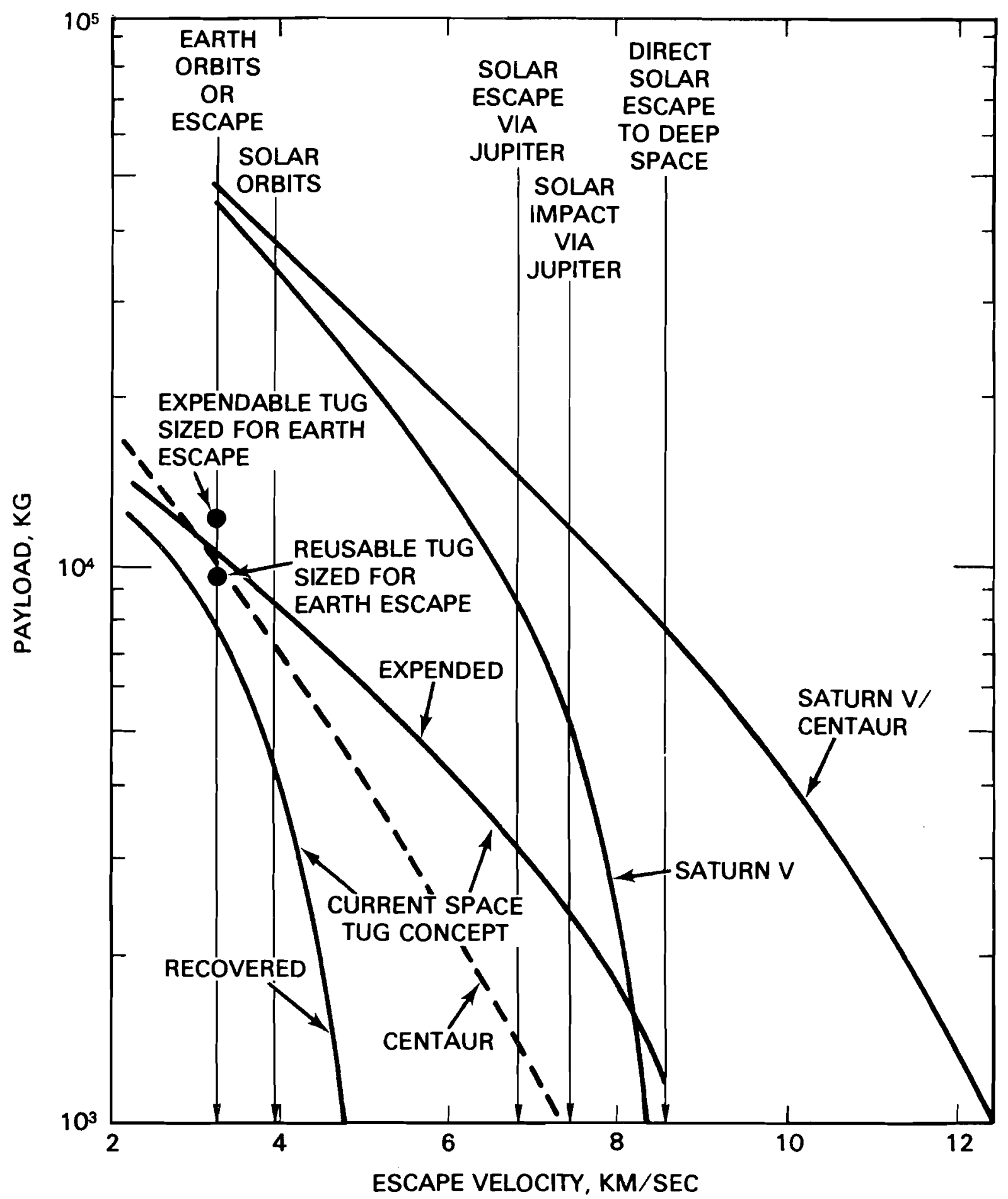

FIGURE 22. Escape Velocity Required for Various Extraterrestrial Disposal Modes and Current Space Vehicle Performance Characteristics 

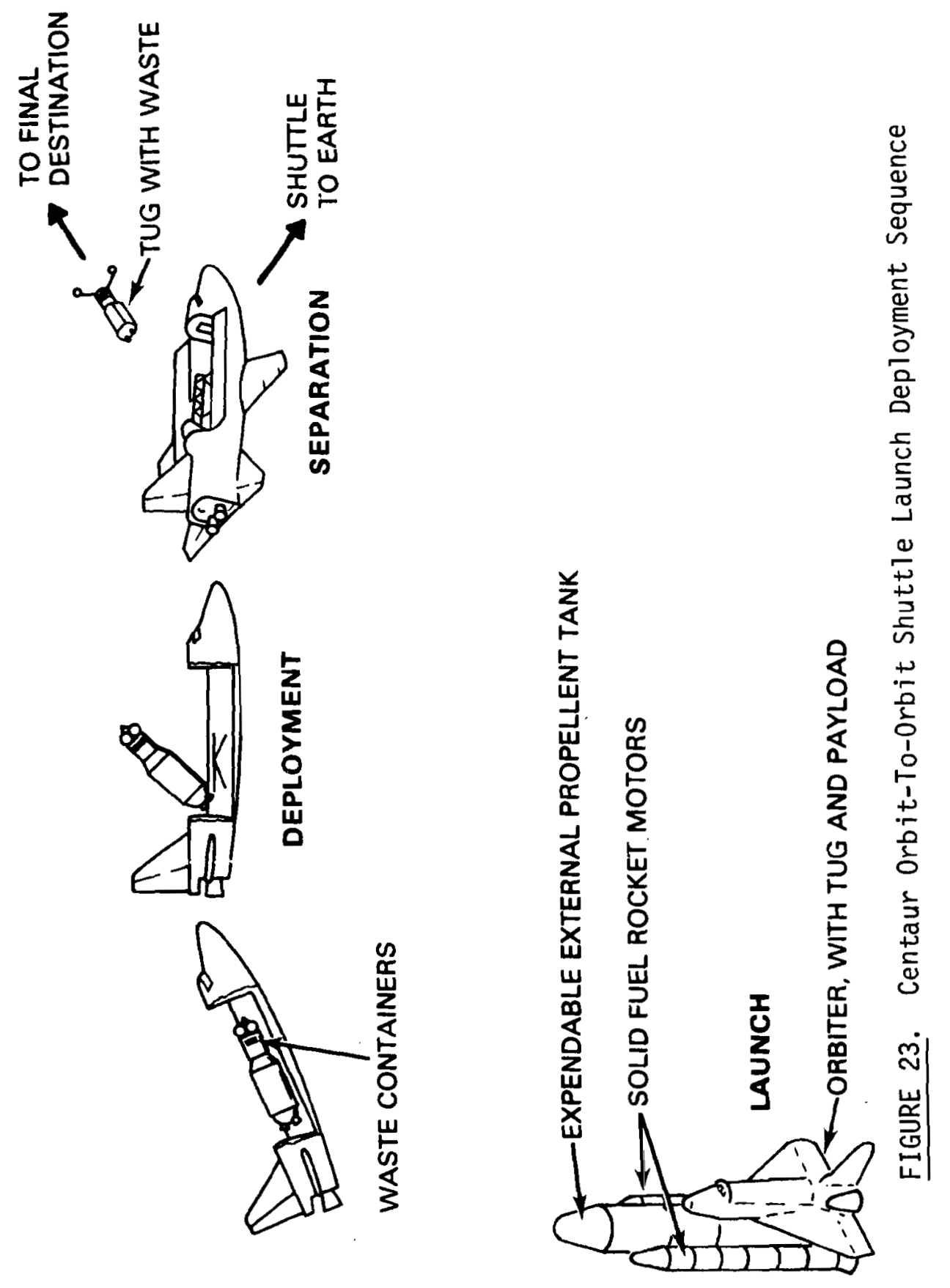
An approximate cost to put material in an earth escape trajectory (but still orbiting the sun) is $\$ 2,000$ per kilogram of gross payload. An approximate cost to escape the solar system to deep space is $\$ 8,000$ per kilogram. Encapsulation will increase the weight of transuranic wastes by a factor of about 20. The cost of separating the transuranic isotopes from waste is expected to be in the range of $\$ 20,000$ per metric ton of original fuel. Encapsulation is expected to cost about $\$ 3,300$ per metric ton of original fuel. Based on these figures, very approximate costs which might be expected for space disposal of wastes are summarized below.

Cost for Extraterrestrial

Elimination of Transuranium Waste

\begin{tabular}{lccc} 
& $\begin{array}{c}\text { High } \\
\text { Earth Orbit }\end{array}$ & $\begin{array}{c}\text { Escape From } \\
\text { Solar System }\end{array}$ \\
\cline { 2 - 2 } Partitioning, \$/MT & 20,000 & & 20,000 \\
Encapsulation, \$/MT & 3,300 & 3,300 \\
Space Flight, \$/MT & $\frac{26,000}{49,300}$ & & $\underline{107,000}$ \\
Total, \$/MT & 130,300
\end{tabular}

A 1000 MWe (Megawatt-Electrical Power) uranium enriched LWR (Light Water Reactor) produces approximately 7 billion kilowatt hours of electricity per year at a generation cost of 5 to 10 mills per kilowatt hour. The nuclear waste for one year's operation contains about 18 kilograms of transuranic wastes, equivalent to about 0.7 kilograms of transuranic material per metric ton of fuel.* The undiscounted cost of extraterrestrial disposal would be about 0.2 mill per kilowatt hour for escape from the earth and about 0.5 mill per kilowatt hour for escape from the solar system. The cost of space disposal of the transuranic isotopes in waste is thus likely to be less than about $10 \%$ of the cost of producing electricity. On a national scale this

* Higher concentrations of transuranic materials are anticipated with plutonium fueled reactors and with the expectation that reactors will operate with fuel recycle and/or for longer times without refueling. 
would be in the millions of dollars per year. Additional costs would be incurred in the management of residues of waste from the partitioning process.

\section{Transmutation}

A possible approach to the management of radioactive waste is the use of nuclear processes themselves to change (transmute) the hazardous longlived radioactive waste constituents into short-lived radioactive waste or nonradioactive isotopes. Transmutation is generally defined as any process whereby a nuclide absorbs or emits radiation and is thereby transformed into another nuclide. The primary transmutation waste management concept under study is based on the radionuclides in waste-absorbing neutrons being converted to less hazardous (i.e., shorter half-life or stable) species.

The feasibility of this concept hinges on achieving:

- A transmutation rate which exceeds the natural rate of radioactive decay

- A reduction in the inventory of radionucliues, and

- A favorable energy balance such that the energy produced from the original nuclear fuel in generating the waste is significantly greater than the energy required for waste transmutation.

The feasibility of transmuting waste is being investigated by dividing radioactive waste into three categories based on the nuclear characteristics of the waste:

- The transuranic elements (TRU) with long half-lives

- The long-lived fission products (half-lives in excess of 100 years)

- The short-lived fission products (half-lives of less than 100 years). Feasibility analyses are being conducted for waste transmutation using neutrons produced by accelerators, fission reactors, fusion reactors, and thermonuclear explosives. 
An initial assessment of the potential of the various transmutation devices under study is summarized in Table 1. The results indicate that recycling transuranic elements in fission reactors shows considerable promise. The transmutation of TRU's and certain long-lived fission products in fusion reactors appears possible when such reactors become available. All of the other devices are less attractive.

PNL efforts are concentrated primarily on investigating transmutation using neutrons produced in fission reactors, with secondary investigations of fusion reactors.

TABLE 1. Summary of Transmutation Device Evaluation

Potential for Transmutation Fission Products

\begin{tabular}{l} 
Device \\
\hline Electron Acceler \\
Proton Accelerator \\
Spallation Accel \\
Thermonuclear Exp \\
Fission Reactors \\
Fusion Reactors \\
* Undetermined
\end{tabular}

On the basis of preliminary investigations a strategy for application of transmutation techniques has been conceived, as shown in Figure 25. This transmutation waste management strategy can be considered a threephase development.

Phase 1 uses the normal nuclear fuel cycle of the fission reactor industry. Basically, this includes the steps of fuel fabrication, reactor irradiation and spent fuel reprocessing. The most significant modification is to partition the waste to retain all actinides in this fuel cycle and thereby convert a significant share of them into fission products by transmutation. The objective of Phase 1, therefore, is to convert long-lived 


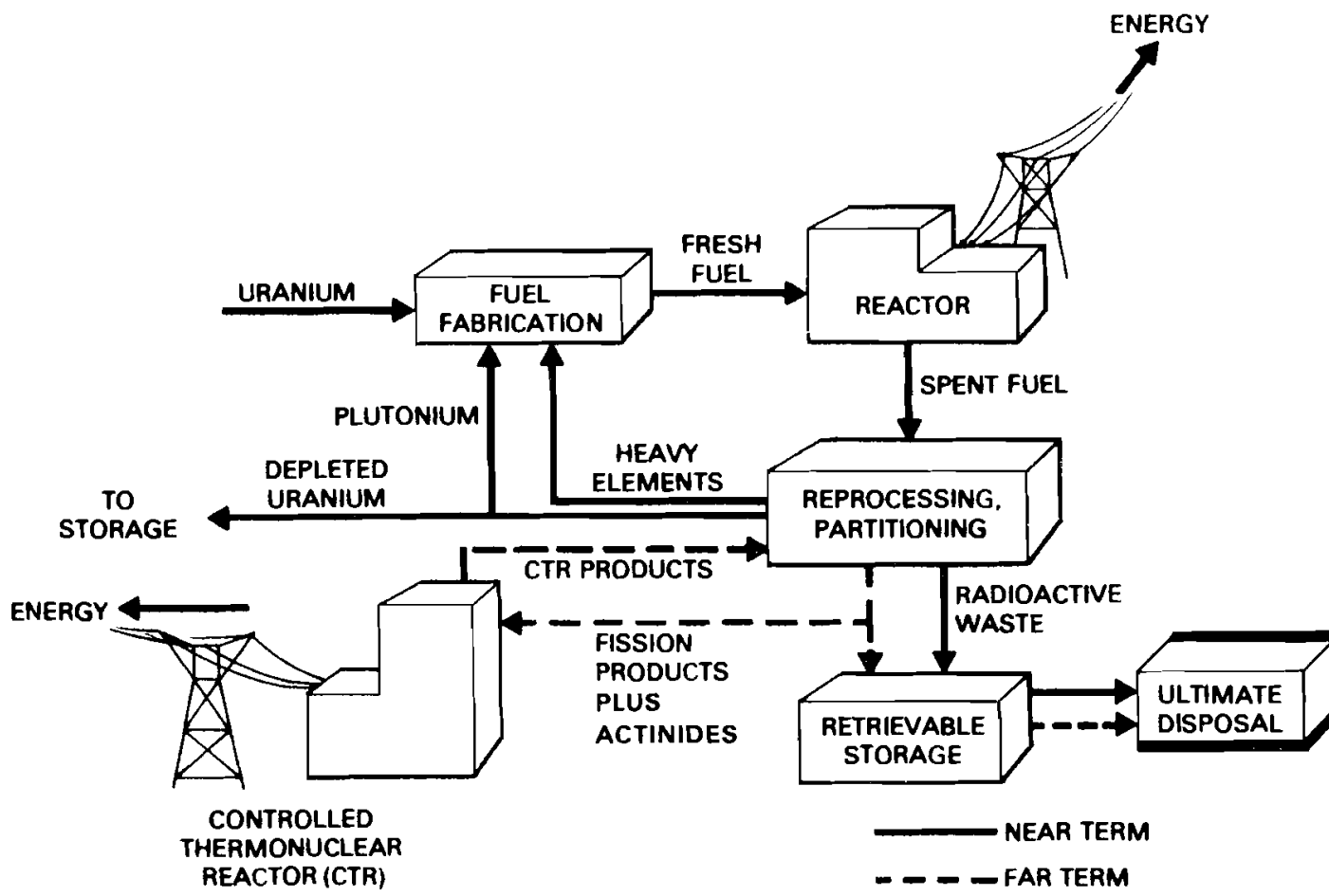

FIGURE 24. Transmutation Waste Management Strategy

actinides to short-lived fission products. This is believed to significantly reduce the time-scale aspects of the waste management problem.

Phase 2 involves temporary storage of fission products for ultimate use in Phase 3 . Thus, retrievable storage naturally complements transmutation.

The Phase 3 objective is to transmute in a fusion reactor the equilibrium inventory of fission products and actinides accumulated from the fission reactor cycle. This final phase results in the ultimate elimination of nearly all radioactive waste constituents.

Transmutation appears to have the potential for eliminating the bulk of long-lived isotopes that are of most concern to the health and safety of the public. The transmutation of TRU's in fission reactors offers a significant reduction of the problem through the conversion of the actinides into fission products. In this case the need for maintaining structural integrity of retrievable storage facilities may be reduced from tens or hundreds of thousands of years to hundreds of years. The fusion reactor offers the 
potential for a nearly complete elimination of the most hazardous waste constituents. Since the waste material resides in the reactors themselves or in retrievable storage, the necessary scrutiny and control is assured.

The development plan for the transmutation concept is first to more fully evaluate the technical and economic feasibility of high-efficiency recovery and recycle of actinides in commercial power reactors, starting with presently operating plants. The technology and related economics for separating the waste into different components (see next section - Waste Partitioning) will be factored into this evaluation. Detailed analyses of reactor behavior will be made wherein a11 transuranic isotopes are included in the calculations. These analyses will provide information on a) the extent to which transuranics can be converted to fission products and b) the penalties which may be associated with maintaining the actinides in the fuel cycle. The early phases of the effort will emphasize those aspects of the problem which have the greatest impact on proving technical and economic feasibility. If the concept appears feasible then an engineering demonstration of the strategy can be undertaken. A much lower level of effort is planned for studying transmutation in fusion reactors since scientific feasibility of achieving a controlled thermonuclear reaction has yet to be proven. 
WASTE PARTITIONING 


\section{WASTE PARTITIONING}

Waste partitioning is a potential process step in which high-level waste from nuclear fuel reprocessing plants is chemically separated into fractions with different characteristics for waste management. The objective of a partitioning process in waste management operations would be to improve safety by making the different waste fractions available for management by selected techniques. This technology is most applicable to extraterrestrial and transmutation waste management concepts.

Partitioning studies are initially directed at isolating the transuranic elements (plutonium, neptunium, americium, and curium) from the rest of the waste constituents (largely fission products). The long-term (periods greater than about 1000 years) potential hazard from terrestriallystored waste could be reduced significantly if the transuranics were

removed from the waste prior to storage. The isolated transuranics then could be managed by another disposal or elimination method.

It appears that the partitioning operation can be accomplished by adaptations of known solvent extraction and ion exchange technology. Figure 26 shows the operations for a partitioning process based on solvent extraction; a flowsheet for ion exchange partitioning would be similar. The various operations shown are necessary due to the chemical behavior of the elements of concern.

Information needed to select and design a preferred partitioning process is being developed. This includes a) determination of process performance requirements (dependent on evaluation of potential hazards from various levels of residual transuranics in the waste), b) development of alternative process flowsheets with details sufficient for comparative evaluation, and $c$ ) determination of specific research and development required to demonstrate a viable process.

The major expected near-term result is selection of a preferred partitioning process. Long-range results expected would include development and demonstration of the process. 


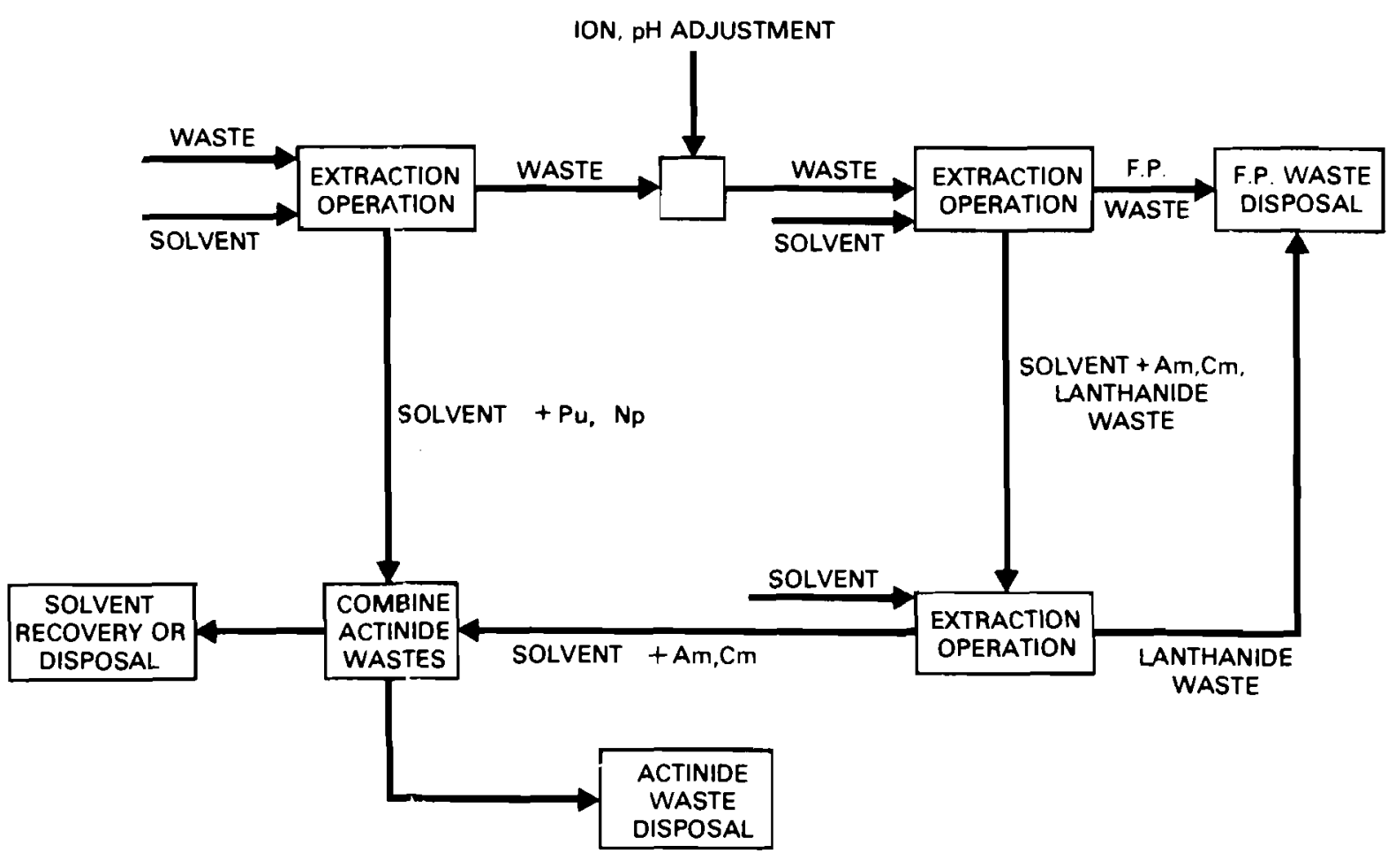

FIGURE 25. Conceptual Flowsheet for Partitioning High-Leve1 Radioactive Waste by Solvent Extraction 